\title{
Passive Control System for Mitigation of Longitudinal Buffeting Responses of a Six-Tower Cable-Stayed Bridge
}

\author{
Fangfang Geng, ${ }^{1}$ Youliang Ding, ${ }^{2}$ and Aiqun $\mathrm{Li}^{2}$ \\ ${ }^{1}$ School of Architecture Engineering, Nanjing Institute of Technology, Nanjing 211167, China \\ ${ }^{2}$ Key Laboratory of Concrete and Prestressed Concrete Structures of Ministry of Education, Southeast University, \\ Nanjing 210096, China
}

Correspondence should be addressed to Fangfang Geng; gengfangfang_1983@163.com

Received 11 November 2015; Accepted 15 May 2016

Academic Editor: Gisella Tomasini

Copyright (C) 2016 Fangfang Geng et al. This is an open access article distributed under the Creative Commons Attribution License, which permits unrestricted use, distribution, and reproduction in any medium, provided the original work is properly cited.

\begin{abstract}
This paper presents an investigation of mitigation of longitudinal buffeting responses of the Jiashao Bridge, the longest multispan cable-stayed bridge in the world. A time-domain procedure for analyzing buffeting responses of the bridge is implemented in ANSYS with the aeroelastic effect included. The characteristics of longitudinal buffeting responses of the six-tower cable-stayed bridge are studied in some detail, focusing on the effects of insufficient longitudinal stiffness of central towers and partially longitudinal constraints between the bridge deck and part of bridge towers. The effectiveness of viscous fluid dampers on the mitigation of longitudinal buffeting responses of the bridge is further investigated and a multiobjective optimization design method that uses a nondominating sort genetic algorithm II (NSGA-II) is used to optimize parameters of the viscous fluid dampers. The results of the parametric investigations show that, by appropriate use of viscous fluid dampers, the top displacements of central towers and base forces of bridge towers longitudinally restricted with the bridge deck can be reduced significantly, with hampering the significant gain achieved in the base forces of bridge towers longitudinally unrestricted with the bridge deck. And the optimized parameters for the viscous fluid dampers can be determined from Pareto-optimal fronts using the NSGA-II that can satisfy the desired performance requirements.
\end{abstract}

\section{Introduction}

For long-span cable-stayed bridges, the multispan cablestayed bridges with three or more towers have been a recent design trend $[1,2]$. Typical examples of this bridge type are the Millau Viaduct Bridge in France, the Maracaibo Bridge in Venezuela, the Rion-Antirion Bridge in Greece, the Mezcala Bridge in Mexico, the Dongting Lake Bridge in China, and the Ting Kau Bridge in Hong Kong [1-4]. The longest multispan cable-stayed bridge in the world is Jiashao Bridge in China, which is a six-tower cable-stayed bridge with the total length of $2680 \mathrm{~m}$.

Compared with a conventional three-span cable-stayed bridge with two towers, there are two major problems in the design of multispan cable-stayed bridges. One is the insufficient longitudinal stiffness that arose from the central tower(s). In the conventional cable-stayed bridges with two towers, each of the towers is connected through outermost stay cables to the fixed anchorage or anchor pier, which can provide effective support to the towers [2]. However, in a multispan cable-stayed bridge, the beneficial effect of the fixed anchorage or anchor pier diminishes for the central tower(s), which results in the insufficient longitudinal stiffness of central towers. Hence, the structural responses of a multispan cable-stayed bridge such as deflections of main girders are increased significantly under unbalanced live loadings compared with a conventional cable-stayed bridge. Another important problem in the design of multispan cablestayed bridges is the large temperature deformation in the long bridge deck. The commonly used structural measure to reduce the temperature effects is the application of partially longitudinal constraints between the bridge deck and part of bridge towers such as the Millau Viaduct Bridge in France and the Jiashao Bridge in China. The application of the partially longitudinal constraint system can improve 


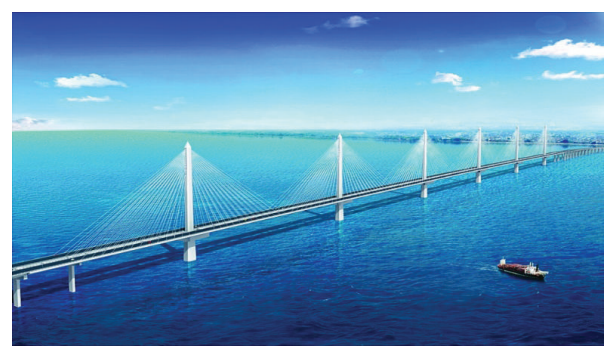

(a)

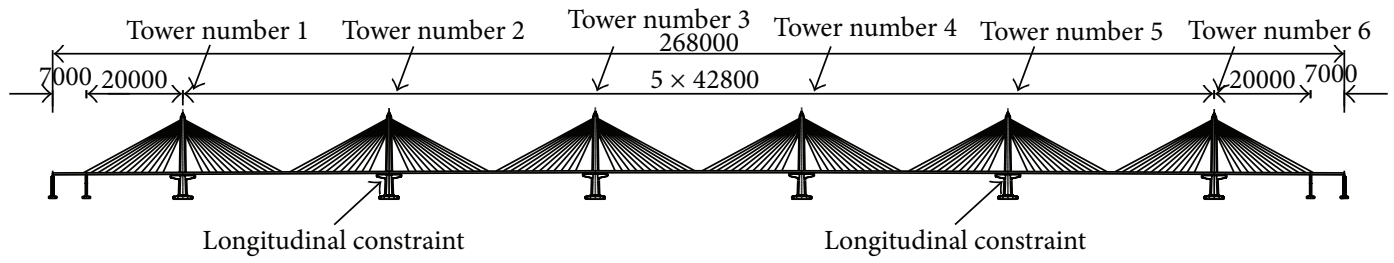

(b)

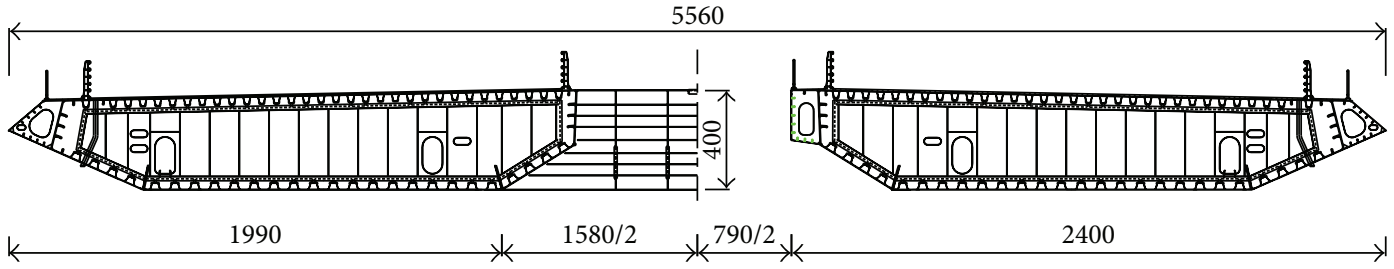

(c)

FIGURE 1: Jiashao Bridge. (a) View of Jiashao Bridge, (b) elevation of Jiashao Bridge (unit: $\mathrm{cm}$ ), and (c) cross section of bridge deck (unit: $\mathrm{cm}$ ).

the static performance of the multitower cable-stayed bridge under temperature action.

To date, an amount of research work had been done on investigating the static performance of the multispan cablestayed bridge under living loadings and temperature action $[1$, $3,4]$. However, studies of the wind-resistant performance of the multispan cable-stayed bridge considering the insufficient longitudinal stiffness of central towers and partially longitudinal constraint system are meager. It is especially desirable to understand the effects of the insufficient longitudinal stiffness of central towers partially longitudinal constraint system on the characteristics of longitudinal buffeting responses of the bridge. And it is also necessary to provide a mitigation scheme for the longitudinal buffeting responses of the multispan cable-stayed bridge. Based on the aforementioned motivation, this paper investigates the performance of viscous fluid dampers for mitigation of longitudinal buffeting response of the Jiashao Bridge, the longest multispan cablestayed bridge in the world. The specific objectives of this study are to (i) investigate the characteristics of longitudinal buffeting responses of the multispan cable-stayed bridge, focusing on the effects of insufficient longitudinal stiffness of central towers and partially longitudinal constraints between the bridge deck and part of bridge towers; (ii) investigate the effects using viscous fluid dampers for mitigation of longitudinal buffeting response of the multispan cable-stayed bridge; and (iii) arrive at the values of optimal design parameters of the viscous fluid dampers for mitigation of longitudinal buffeting responses of the bridge using a multiobjective optimization design method.

\section{Bridge Description}

The subject of this study is Jiashao Bridge shown in Figure 1(a), which is a six-tower cable-stayed bridge that crosses the Hangzhou Bay, along the highway between Jiaxing and Shaoxing in China. The total length of the bridge is $2680 \mathrm{~m}$ with the span arrangement of $70 \mathrm{~m}+200 \mathrm{~m}+5 \times$ $428 \mathrm{~m}+200 \mathrm{~m}+70 \mathrm{~m}$, which is the longest multispan cablestayed bridge in the world. Figure 1(b) shows the schematic elevation view of the Jiashao Bridge. In order to overcome the problem of large temperature deformation in the long bridge deck, the partially longitudinal constraint system is applied in the design of Jiashao Bridge. As shown in Figure 1(b), the longitudinal constraints are applied to restrict the bridge deck from moving in the longitudinal direction at bridge towers number 2 and number 5, respectively. And there are no longitudinal constraints between the bridge deck and other bridge towers. The role of such partially longitudinal constraint system is to reduce the temperature-induced longitudinal deformation in the bridge deck. Figure 1(c) shows the typical deck cross section of the bridge.

\section{Dynamic Finite Element Model}

A three-dimensional finite element model of the Jiashao Bridge has been developed by use of the commercial software 


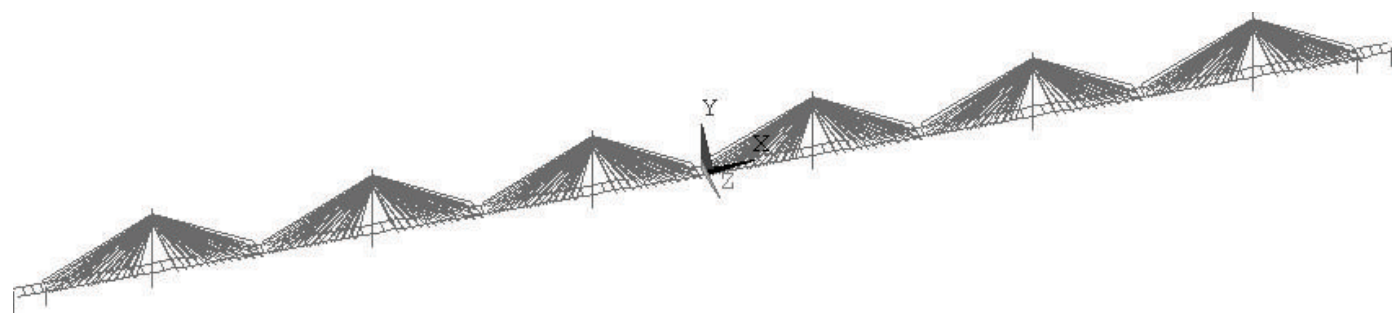

Figure 2: Finite element model of Jiashao Bridge.

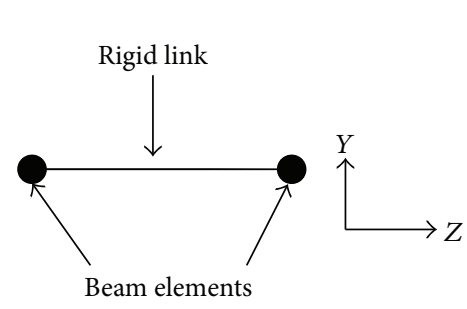

(a) Rigid links connecting two steel box girders

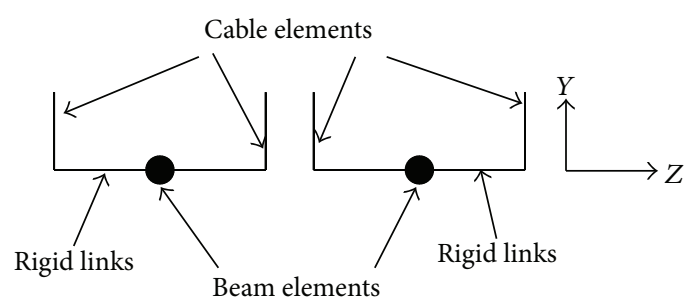

(b) Rigid links connecting stay cables

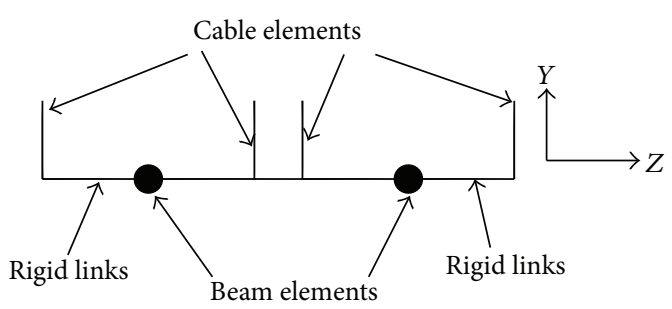

(c) Rigid links simultaneously connecting two steel box girders and stay cables

FIgURE 3: Detailed finite element modeling for rigid links.

package ANSYS [5]. The finite element model involves 1402 nodes and 1872 elements, as shown in Figure 2. In this model, a double-girder model is used to simulate the bridge deck system when conducting dynamic analysis. The two steel box girders are modeled as Timoshenko's beam elements with 6 degrees of freedom (DOFs) at each node, which account for transverse shear deformation, biaxial bending, and axial strain. And the cross-beams connecting two steel box girders are modeled as rigid links at $30 \mathrm{~m}$ intervals as shown in Figure 3(a). The bridge towers and piers are also modeled as Timoshenko's beam elements. A 2-node truss element is used to simulate the stay cables, which accounts for only tension and no compression based on the real condition. Considering the geometric stiffness of stay cables under dead loading, the Ernst equivalent elastic modulus for stay cables is adopted [6]. Rigid links at $15 \mathrm{~m}$ intervals are used to connect the cables in four planes to the girders as shown in Figure 3(b). Figure 3(c) further shows the case of rigid links simultaneously connecting two steel box girders and four stay cables.

The detailed finite element modeling for the constraints between the girders and towers (piers) are described as follows.

(i) Modeling of constraints between the girders and towers: As shown in Figure 4(a), constraints are applied to restrict the deck from moving in the longitudinal, lateral, and vertical directions at bridge towers number 2 and number 5 . Thus, the constraint equations of DOFs for the nodes N1 N 3 shown in Figure 4(a) can be defined as $U X(\mathrm{~N} 1)=U X(\mathrm{~N} 2)=$ $U X(\mathrm{~N} 3), U Y(\mathrm{~N} 1)=U Y(\mathrm{~N} 2)=U Y(\mathrm{~N} 3), U Z(\mathrm{~N} 1)=U Z(\mathrm{~N} 2)=$ $U Z(\mathrm{~N} 3)$. It should be noted that, for other towers number 1 , number 3 , number 4 , and number 6 , constraints are applied to restrict the deck from moving in the lateral and vertical directions. Thus, the constraint equations of DOFs for the nodes $\mathrm{N} 1 \sim \mathrm{N} 3$ can be defined as $U Y(\mathrm{~N} 1)=U Y(\mathrm{~N} 2)=U Y(\mathrm{~N} 3)$, $U Z(\mathrm{~N} 1)=U Z(\mathrm{~N} 2)=U Z(\mathrm{~N} 3)$

(ii) Modeling of constraints between the girders and piers in each side span: As shown in Figure 4(b), constraints are applied to restrict the motion of bridge deck at all bridge piers including auxiliary pier and end pier to allow only longitudinal displacement $X$ and rotations about the $y$ and $z$ axes. Thus, the constraint equations of DOFs for the nodes N1 N6 shown in Figure 4(b) can be defined as $U Y(\mathrm{~N} 1)=$ $U Y(\mathrm{~N} 2)=U Y(\mathrm{~N} 3), U Y(\mathrm{~N} 4)=U Y(\mathrm{~N} 5)=U Y(\mathrm{~N} 6), U Z(\mathrm{~N} 1)=$ $U Z(\mathrm{~N} 2)=U Z(\mathrm{~N} 3), U Z(\mathrm{~N} 4)=U Z(\mathrm{~N} 5)=U Z(\mathrm{~N} 6), R O T X(\mathrm{~N} 1)$ $=\operatorname{ROTX}(\mathrm{N} 2)=\operatorname{ROTX}(\mathrm{N} 3), \operatorname{ROTX}(\mathrm{N} 4)=\operatorname{ROTX}(\mathrm{N} 5)=$

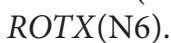

The modal analysis of the Jiashao Bridge is essential to determine the buffeting responses in succeeding dynamic analysis subjected to wind loadings. It should be noted that 


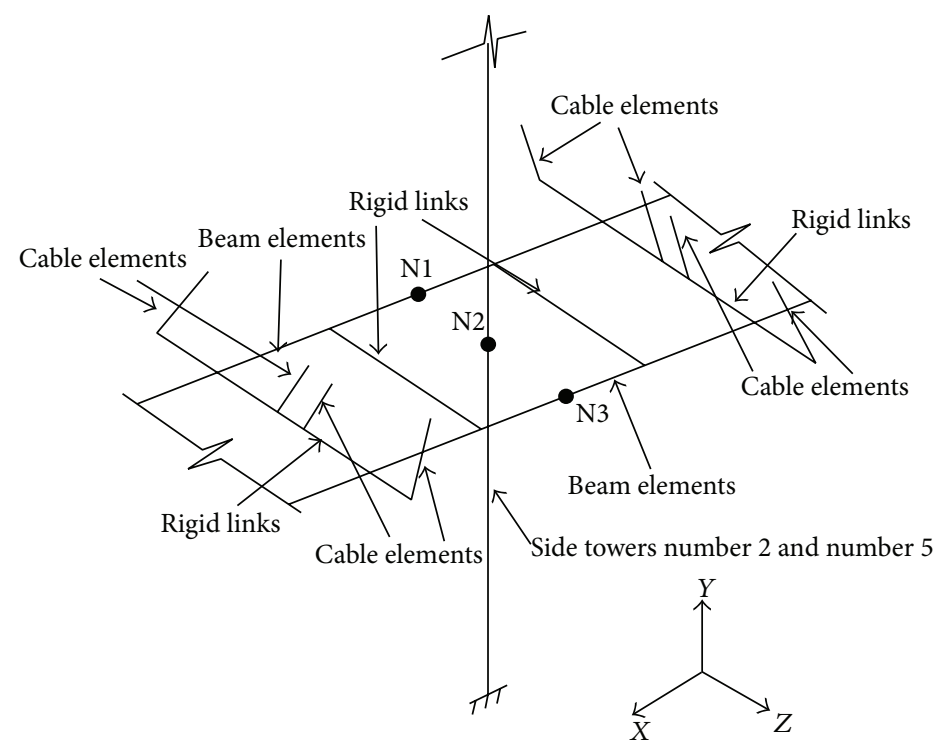

(a) Constraints between the girders and side towers number 2 and number 5

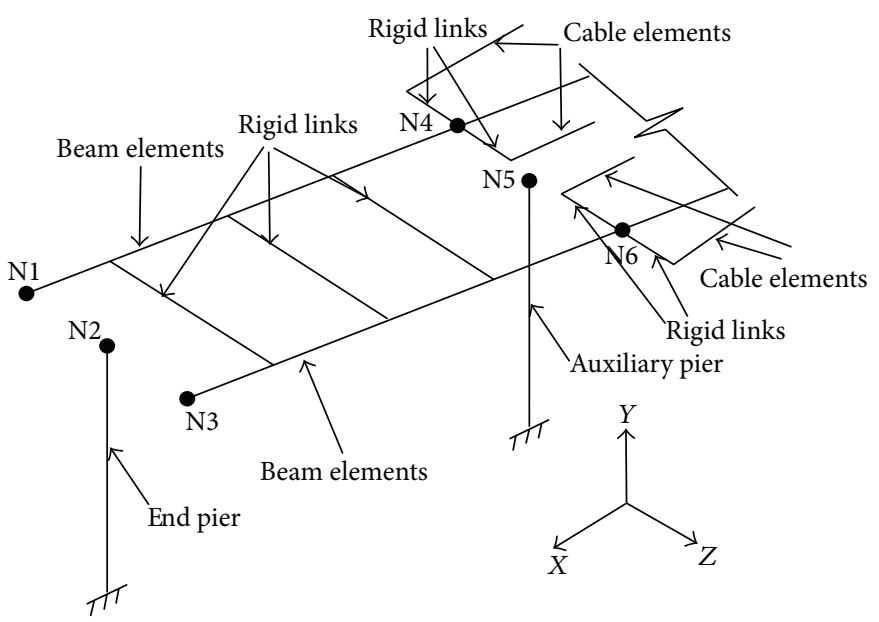

(b) Auxiliary pier and end pier in each side span

FIgURE 4: Detailed finite element modeling for the constraints between the girders and towers (piers).

the modal analysis of bridge is followed starting from the static equilibrium state due to dead load and cable pretension, which is obtained by geometrically nonlinear analysis of the bridge. The LANCZOS eigenvalue solver is then adopted for modal analysis. Main vibrations modes of finite element model are listed in Table 1 and part of them are shown in Figure 5.

\section{Longitudinal Buffeting Responses of the Bridge}

\subsection{Simulation of the Wind Field}

4.1.1. Simplified Wind Field at Bridge Site. To perform the nonlinear buffeting analysis of the bridge in the time domain, eight one-dimensional independent multivariable stochastic wind fields are simulated based on the structural configuration as listed in Table 2. One of them is along the bridge deck, one is across the bridge deck, and the other six are across the six bridge towers, respectively. The bridge deck has 95 simulation points, spaced at $30 \mathrm{~m}$ from left to right. And each bridge tower is divided into equal intervals of $10 \mathrm{~m}$ from top to bottom, which results in 16 simulation points.

4.1.2. Design Wind-Field Parameters. The design mean wind speed $\bar{U}(z)$ at height $z$ follows the power-law model:

$$
\bar{U}(z)=39.3\left(\frac{z}{10}\right)^{0.16},
$$

where the design wind speed $39.3 \mathrm{~m} / \mathrm{s}$ at the height of $10 \mathrm{~m}$ has a return period of 100 years. As for the design wind spectra, the autospectra adopted for longitudinal and vertical components are Kaimal spectrum and Panofsky spectrum, respectively. 
TABLE 1: Vibration modes of finite element model of Jiashao Bridge.

\begin{tabular}{lcc}
\hline Mode number & Frequency/Hz & Description \\
\hline 1 & 0.2274 & 1st symmetric vertical bending of bridge deck + symmetric longitudinal bending of bridge tower \\
2 & 0.2615 & 1st antisymmetric vertical bending of bridge deck + antisymmetric longitudinal bending of bridge tower \\
3 & 0.2894 & 1st symmetric lateral bending of bridge tower \\
4 & 0.2907 & 1st antisymmetric lateral bending of bridge tower \\
5 & 0.2928 & 2nd symmetric lateral bending of bridge tower \\
6 & 0.2950 & 2nd antisymmetric lateral bending of bridge tower \\
7 & 0.2965 & 3rd symmetric lateral bending of bridge tower \\
8 & 0.2970 & 3rd antisymmetric lateral bending of bridge tower \\
9 & 0.3085 & 2nd symmetric vertical bending of bridge deck + symmetric longitudinal bending of bridge tower \\
10 & 0.3618 & 2nd antisymmetric vertical bending of bridge deck + antisymmetric longitudinal bending of bridge tower \\
21 & 0.7087 & 1st symmetric lateral bending of bridge deck + symmetric lateral bending of bridge tower \\
33 & 0.8956 & 1st antisymmetric lateral bending of bridge deck + antisymmetric lateral bending of bridge tower \\
43 & 1.1361 & 1st symmetric torsion of bridge deck \\
44 & 1.1389 & 2nd symmetric torsion of bridge deck \\
\hline
\end{tabular}

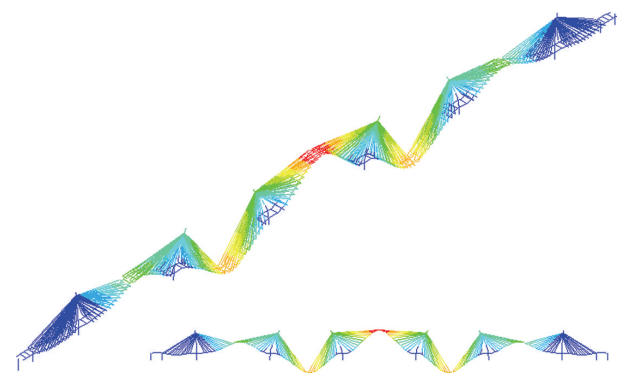

(a)

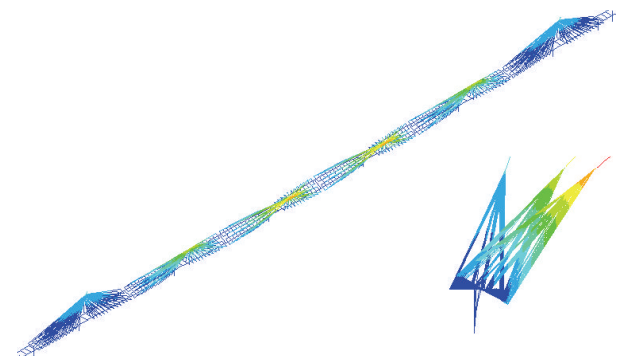

(c)

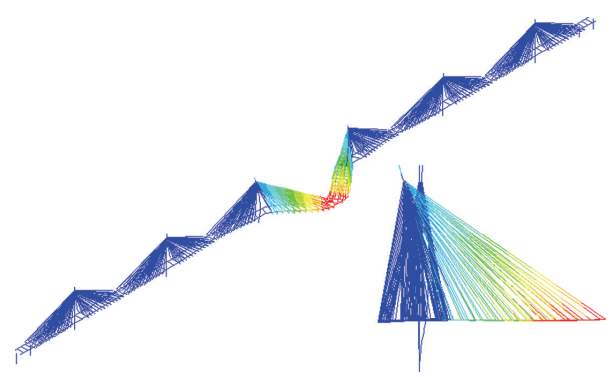

(e)

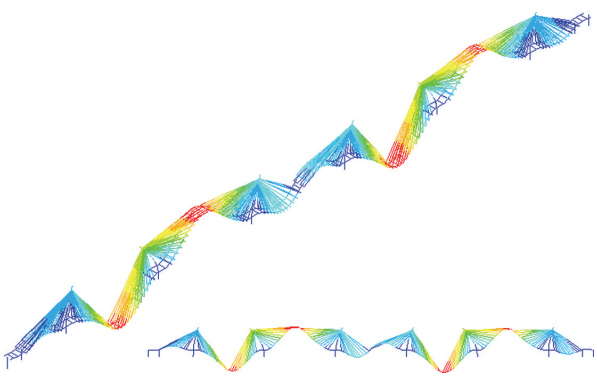

(b)

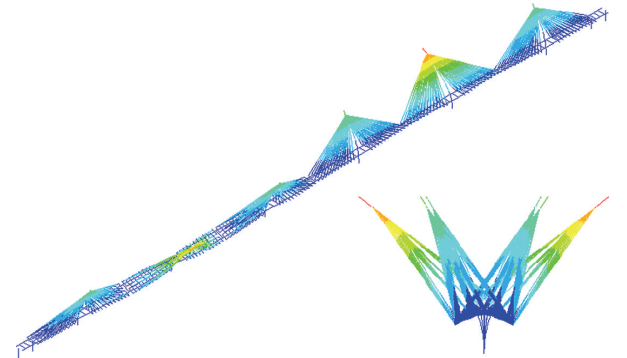

(d)

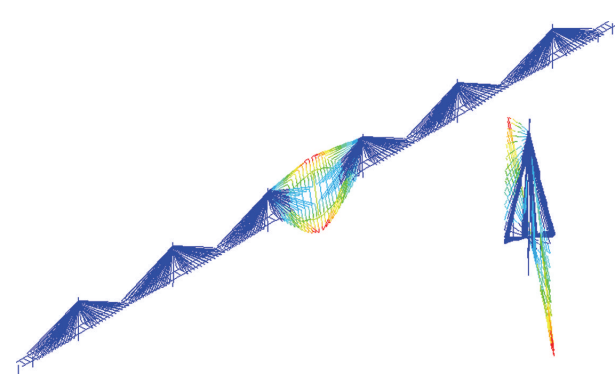

(f)

FIGURE 5: Mode shapes of the bridge. (a) 1st symmetric vertical bending of bridge deck + symmetric longitudinal bending of bridge tower, (b) 1st antisymmetric vertical bending of bridge deck + antisymmetric longitudinal bending of bridge tower, (c) 1st symmetric lateral bending of bridge tower, (d) 1st antisymmetric lateral bending of bridge tower, (e) 1st symmetric lateral bending of bridge deck + symmetric lateral bending of bridge tower, and (f) 1st symmetric torsion of bridge deck. 
TABLE 2: Simplified simulation of the wind field.

\begin{tabular}{lcccc}
\hline Number & Location & Component of wind velocity & Spacing & Number of simulation points \\
\hline 1 & Bridge deck & Transverse component $u$ & $30 \mathrm{~m}$ & 95 \\
2 & Bridge deck & Vertical component $w$ & $30 \mathrm{~m}$ & 95 \\
3 & Tower number 1 & Transverse component $u$ & $10 \mathrm{~m}$ & 16 \\
4 & Tower number 2 & Transverse component $u$ & $10 \mathrm{~m}$ & 16 \\
5 & Tower number 3 & Transverse component $u$ & $10 \mathrm{~m}$ & 16 \\
6 & Tower number 4 & Transverse component $u$ & $10 \mathrm{~m}$ & 16 \\
8 & Tower number 5 & Transverse component $u$ & $10 \mathrm{~m}$ & 16 \\
\hline
\end{tabular}

Kaimal spectrum:

$$
\frac{n S_{u}}{u_{*}^{2}}=\frac{200 f}{(1+50 f)^{5 / 3}}
$$

Panofsky spectrum:

$$
\frac{n S_{w}}{u_{*}^{2}}=\frac{6 f}{(1+4 f)^{2}},
$$

where $S_{u}$ and $S_{w}$ are spectral-density function of longitudinal velocity fluctuation and vertical velocity fluctuation, respectively; $n$ is fluctuation frequency; $f=n z / \bar{U}(z)$ is the Monin coordinate; $u_{*}$ is the friction velocity.

The following empirical exponential coherence function is adopted for the velocity cross-spectrum [7]

$$
\begin{aligned}
& \gamma_{j k}(\omega) \\
& =\exp \left\{-\frac{\omega}{2 \pi} \frac{\left[C_{z}^{2}\left(z_{j}-z_{k}\right)^{2}+C_{x}^{2}\left(x_{j}-x_{k}\right)^{2}\right]^{1 / 2}}{(1 / 2)\left[\bar{U}\left(z_{j}\right)+\bar{U}\left(z_{k}\right)\right]}\right\},
\end{aligned}
$$

where $z_{j}$ and $x_{j}$ are coordinates in the $z$ - and $x$-directions, respectively; $C_{z}$ and $C_{x}$ are 8.3 and 6.4 for longitudinal turbulence components and 3.8 and 4.8 for vertical turbulence components. It should be noted that the coherence between the longitudinal and vertical components is disregarded in the present study.

4.1.3. Wind-Field Simulation at Bridge Deck and Towers. The wind velocity at each simulation point of bridge deck and towers is the sum of the mean wind velocity and turbulent fluctuation around the mean wind velocity. In the present study, the fluctuating wind velocity is taken as realization of a multivariate Gaussian vector process having zero mean and known fixed spectral densities at all simulation points [8]. Thus, the longitudinal and vertical fluctuating velocities in the overall wind field are modeled as 191-variate vector process, $\mathbf{u}(t)$, and a 95-variate vector process, $\mathbf{w}(t)$, respectively. By using the improved Deodatis simulation method $[8,9]$, the longitudinal and vertical fluctuating wind-velocity samples at 95 points on the bridge deck and 96 points on the bridge towers are simulated. The parameters used in the simulation are as follows: the cut-off frequency $\omega_{u}=5 \pi \mathrm{rad} / \mathrm{s}$, the number of fast-Fourier transform $N=1024$, and time interval $\Delta t=0.2 \mathrm{~s}$. Figures 6 and 7 illustrate the autospectra and correlation functions of the longitudinal fluctuating velocities for two points, Point 1 and Point 15, at the bridge tower number 3 with a distance of $150 \mathrm{~m}$. As can be seen from the figure, the simulated autospectra and correlation functions are in well agreement with the targets.

\subsection{Longitudinal Buffeting Responses of the Bridge}

4.2.1. Buffeting Analysis Method. The simulated fluctuating wind speed time-histories are used as inputs to obtain the buffeting responses of the Jiashao Bridge in the time domain. In this section, the buffeting analysis method is introduced briefly. Consider a deck section in a turbulent flow and in motion at an instant time $t$. Based on the quasi-steady theory, the aerodynamic forces per unit span in the global axes are composed of three wind loading components, namely, the steady aerodynamic forces, the buffeting forces due to the fluctuating wind components $u$ and $w$, and the selfexcited forces induced by interaction between bridge and wind motions [10-12]. The steady aerodynamic forces are expressed as

$$
\begin{aligned}
F_{y}^{\text {st }}(t) & =\frac{1}{2} \rho U^{2} B C_{D}, \\
F_{z}^{\text {st }}(t) & =\frac{1}{2} \rho U^{2} B C_{L}, \\
M_{x}^{\text {st }}(t) & =-\frac{1}{2} \rho U^{2} B^{2} C_{M},
\end{aligned}
$$

where $F_{y}^{\text {st }}, F_{z}^{\text {st }}$, and $M_{x}^{\text {st }}$ are three components in the horizontal, vertical, and rotational directions; $\rho$ is the air density and $\rho=1.225 \mathrm{~kg} / \mathrm{m}^{3}$ in this study; $B(=55.6 \mathrm{~m})$ is the deck width; $U$ is the mean wind velocity; $C_{D}, C_{L}$, and $C_{M}$ are the drag force, lift force, and pitching moment coefficients. The aerodynamic force coefficients are measured through the wind-tunnel tests. In this study $C_{D}, C_{L}$, and $C_{M}$ are taken as $0.0943,-0.1627$, and 0.0088 , respectively, at $0^{\circ}$ wind attack angle. 


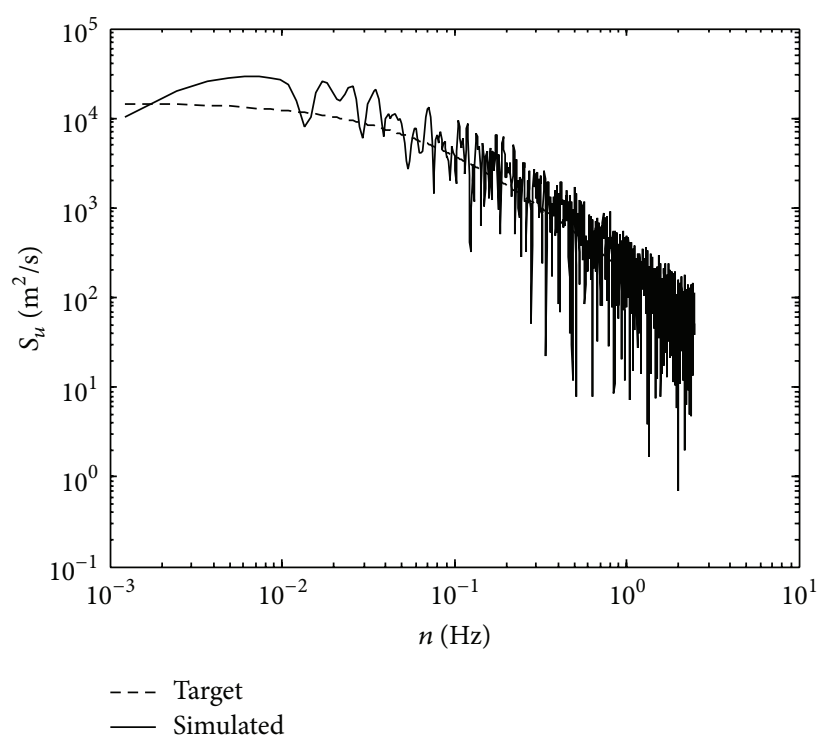

(a)

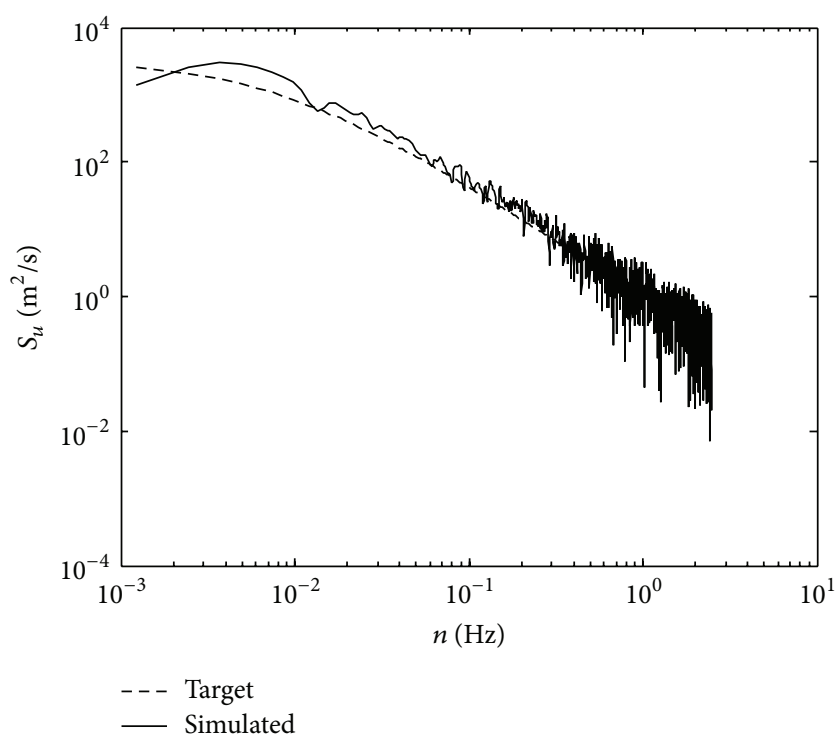

(b)

FIGURE 6: Autospectra of longitudinal fluctuating wind velocities at bridge tower number 3. (a) Autospectrum of Point 1 and (b) autospectrum of Point 15.

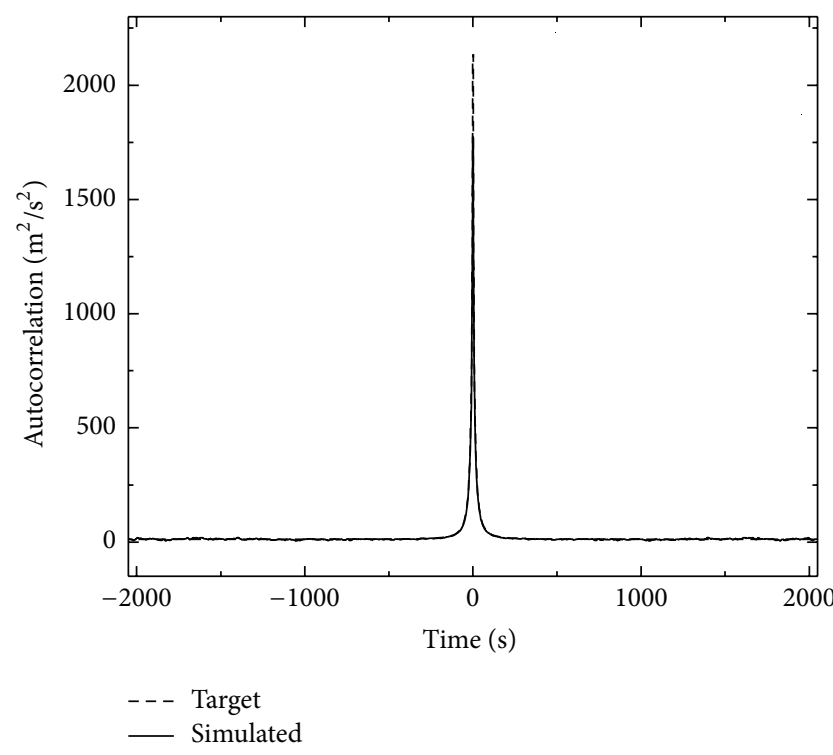

(a)

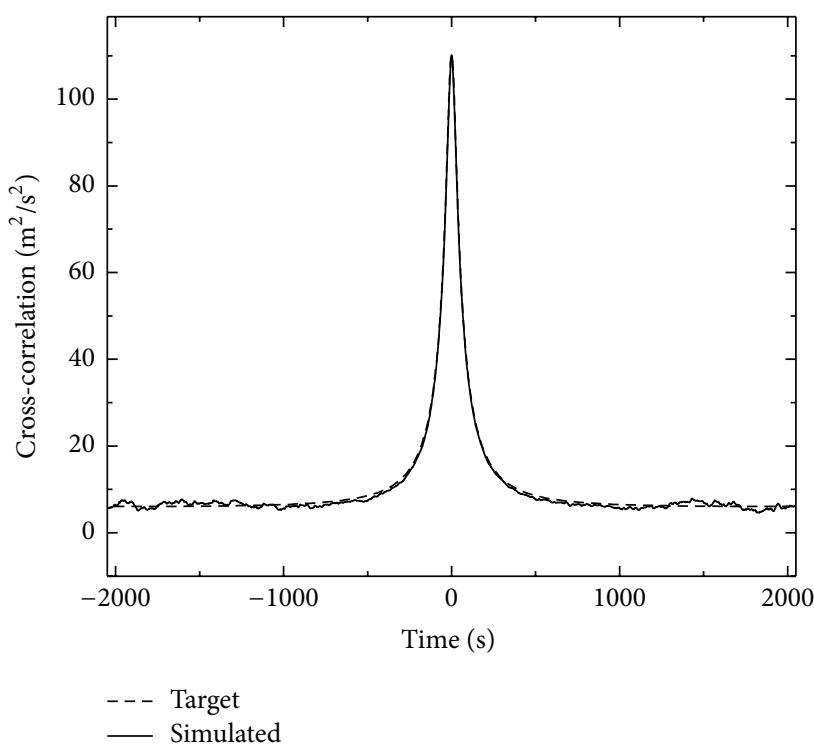

(b)

FIgURE 7: Correlation functions of longitudinal fluctuating wind velocities at bridge tower number 3. (a) Autocorrelation of Point 1 and (b) cross-correlation between Points 1 and 15 with a distance of $150 \mathrm{~m}$.

The self-excited forces are expressed as

$$
\begin{aligned}
& F_{y}^{\text {se }}(t)=\frac{1}{2} \rho U^{2}(2 B)\left[K P_{1}^{*} \frac{\dot{r}_{y}}{U}+K P_{2}^{*} \frac{B \dot{r}_{\theta}}{U}+K^{2} P_{3}^{*} r_{\theta}\right. \\
& \left.+K^{2} P_{4}^{*} \frac{r_{y}}{B}+K P_{5}^{*} \frac{\dot{r}_{z}}{U}+K^{2} P_{6}^{*} \frac{r_{z}}{B}\right], \\
& F_{z}^{\text {se }}(t)=\frac{1}{2} \rho U^{2}(2 B)\left[K H_{1}^{*} \frac{\dot{r}_{z}}{U}+K H_{2}^{*} \frac{B \dot{r}_{\theta}}{U}+K^{2} H_{3}^{*} r_{\theta}\right. \\
& \left.+K^{2} H_{4}^{*} \frac{r_{z}}{B}+K H_{5}^{*} \frac{\dot{r}_{y}}{U}+K^{2} H_{6}^{*} \frac{r_{y}}{B}\right],
\end{aligned}
$$

$$
\begin{aligned}
& M_{x}^{\mathrm{se}}(t)=\frac{1}{2} \rho U^{2}\left(2 B^{2}\right)\left[K A_{1}^{*} \frac{\dot{r}_{z}}{U}+K A_{2}^{*} \frac{B \dot{r}_{\theta}}{U}\right. \\
& \left.+K^{2} A_{3}^{*} r_{\theta}+K^{2} A_{4}^{*} \frac{r_{z}}{B}+K A_{5}^{*} \frac{\dot{r}_{y}}{U}+K^{2} A_{6}^{*} \frac{r_{y}}{B}\right],
\end{aligned}
$$

where $F_{y}^{\text {se }}, F_{z}^{\text {se }}$, and $M_{x}^{\text {se }}$ are three components in the horizontal, vertical, and rotational directions; $K=\omega B / U$ is the reduced circular frequency of motion and $\omega$ is the circular frequency; $r_{y}, r_{z}$, and $r_{\theta}$ are the horizontal, vertical, and torsional displacements, respectively; $P_{i}^{*}, H_{i}^{*}$, and $A_{i}^{*}(i=$ $1,2, \ldots, 6)$ are the dimensionless flutter derivatives, which are 
characteristic cross-sectional properties expressed in terms of the reduced wind speed $\widetilde{U}=U /(f B)$ and $f$ is the natural frequency. The flutter derivatives at $0^{\circ}$ wind attack angle under different reduced wind speed $\widetilde{U}$ are obtained through the wind-tunnel tests and listed in the literature [13].

The buffeting forces are expressed as

$$
\begin{aligned}
& F_{y}^{\mathrm{b}}(t) \\
& \quad=\frac{1}{2} \rho U^{2} B\left[2 C_{D} \chi_{D u} \frac{u(t)}{U}+\left(C_{D}^{\prime}-C_{L}\right) \chi_{D w} \frac{w(t)}{U}\right], \\
& F_{z}^{\mathrm{b}}(t) \\
& \quad=\frac{1}{2} \rho U^{2} B\left[2 C_{L} \chi_{L u} \frac{u(t)}{U}+\left(C_{L}^{\prime}+C_{L}\right) \chi_{L w} \frac{w(t)}{U}\right], \\
& M_{x}^{\mathrm{b}}(t)=\frac{1}{2} \rho U^{2} B^{2}\left[2 C_{M} \chi_{M u} \frac{u(t)}{U}+C_{M}^{\prime} \chi_{M w} \frac{w(t)}{U}\right],
\end{aligned}
$$

where $C_{D}^{\prime}, C_{L}^{\prime}$, and $C_{M}^{\prime}$ are the derivates of $C_{D}, C_{L}$, and $C_{M}$ with respect to wind attack angle, respectively; $u(t)$ and $w(t)$ are the longitudinal and vertical turbulence wind components, respectively; $\chi_{L u}, \chi_{L w}, \chi_{D u}, \chi_{D w}, \chi_{M u}$, and $\chi_{M w}$ are the six complex aerodynamic admittance functions which are functions of reduced frequency. In this study, the $C_{D}^{\prime}, C_{L}^{\prime}$, and $C_{M}^{\prime}$ are taken as $0.1934,5.5119$, and 0.8337 , respectively, at $0^{\circ}$ wind attack angle. It should be noted that the effect of the aerodynamic admittance is disregarded because it was not available from wind-tunnel tests. Thus, the values of six aerodynamic admittance functions are all taken as unity conservatively.

Based on (5) (7c), investigations on time-domain buffeting analysis have been done by several researchers in recent years $[11,12,14]$. In the present study, the buffeting analysis is carried out in the software package ANSYS with the following steps $[12,15]$ : (1) A 3D finite element model of the bridge is established using the software package ANSYS. (2) The selfexcited aerodynamic forces acting on unit span of the bridge deck according to $(6 a)-(6 c)$ can be modeled as elemental aeroelastic stiffness and aeroelastic damping matrices by the user-defined Matrix27 element in ANSYS [11, 12, 14]. The detailed procedure to calculate the self-excited aerodynamic forces using user-defined Matrix27 element in ANSYS is demonstrated in detail by Wang et al. [12]. (3) The steady aerodynamic forces and buffeting forces are calculated by (5), (7a), (7b), and (7c), respectively. (4) The self-excited aerodynamic forces, buffeting forces, and steady aerodynamic forces are applied as external loadings to the structural model to analyze the buffeting responses of the bridge in time domain $[11,12]$.

4.2.2. Longitudinal Buffeting Responses of the Bridge. The buffeting response analysis of the Jiaoshao Bridge was carried out at the design wind velocity of $49.72 \mathrm{~m} / \mathrm{s}$ at the bridge deck for the return period of 100 years. The longitudinal buffeting response quantities selected are listed in Table 3. It should be noted that considering the dynamic coupling between vertical bending of the bridge deck and longitudinal bending of bridge tower as shown in Table 1 the vertical
TABLE 3: Longitudinal buffeting response quantities.

\begin{tabular}{ll}
\hline Response quantities & Positions on the bridge structure \\
\hline $\begin{array}{l}\text { Longitudinal base shear of the } \\
\text { bridge tower }\end{array}$ & $\begin{array}{l}\text { On the bottom of bridge towers } \\
\text { number 1 number } 6\end{array}$ \\
$\begin{array}{l}\text { Longitudinal base moment of } \\
\text { the bridge tower }\end{array}$ & $\begin{array}{l}\text { On the bottom of bridge towers } \\
\text { number 1 number } 6\end{array}$ \\
$\begin{array}{l}\text { Longitudinal top displacement } \\
\text { of the bridge tower }\end{array}$ & $\begin{array}{l}\text { On the top of bridge towers } \\
\text { number 1 number } 6\end{array}$ \\
$\begin{array}{l}\text { Vertical displacement of the } \\
\text { bridge deck }\end{array}$ & $\begin{array}{l}\text { In the middle of the spans } \\
\text { between two towers }\end{array}$ \\
\hline
\end{tabular}

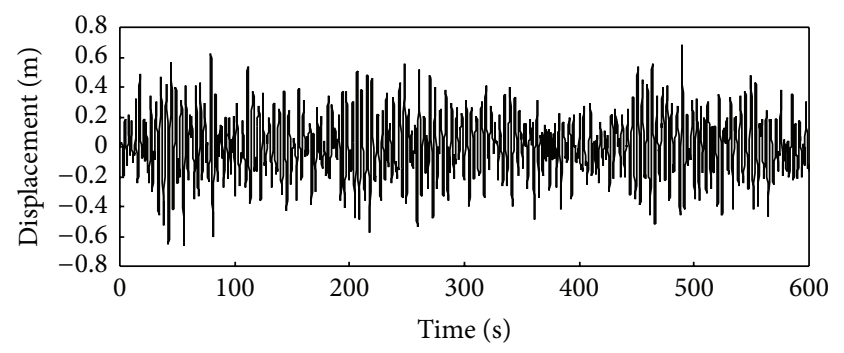

FIGURE 8: Time-history of vertical buffeting displacement.

TABLE 4: RMS vertical displacements of the bridge deck (unit: $m$ ).

\begin{tabular}{lc}
\hline $\begin{array}{l}\text { In the middle of the span between two } \\
\text { towers }\end{array}$ & $\begin{array}{c}\text { RMS vertical } \\
\text { displacement }\end{array}$ \\
\hline Towers number 1 and number 2 & 0.1638 \\
Towers number 2 and number 3 & 0.1847 \\
Towers number 3 and number 4 & 0.2065 \\
Towers number 4 and number 5 & 0.1771 \\
Towers number 5 and number 6 & 0.1611 \\
\hline
\end{tabular}

displacement of the bridge deck is also selected as longitudinal buffeting response quantity. Figure 8 shows the timehistories of vertical buffeting displacement in the middle of the girder span between bridge towers number 3 and number 4 . The root-mean-square (RMS) buffeting responses are further calculated to evaluate the longitudinal windresistance performance of the multispan cable-stayed bridge. Figure 9 shows the RMS longitudinal buffeting responses of bridge towers. Table 4 shows RMS vertical displacements of bridge deck.

From Figure 9 and Table 3 the following can be seen. (i) The RMS base shears and RMS base moments of the bridge towers number 2 and number 5 in the partially longitudinal constraint system are approximately 3.6 times as those in the other towers. Thus, part of bridge towers longitudinally restricted with the bridge deck results in the concentration effects of base shear and moment. (ii) The RMS top displacements of central towers (towers number 2, number 3, number 4, and number 5) are approximately 1.7 times as those of side towers (tower number 1 and number 6). This is because the beneficial effect of the anchor piers diminishes for the central towers and hence the longitudinal stiffness of the central towers is smaller than that of the side towers [2]. 


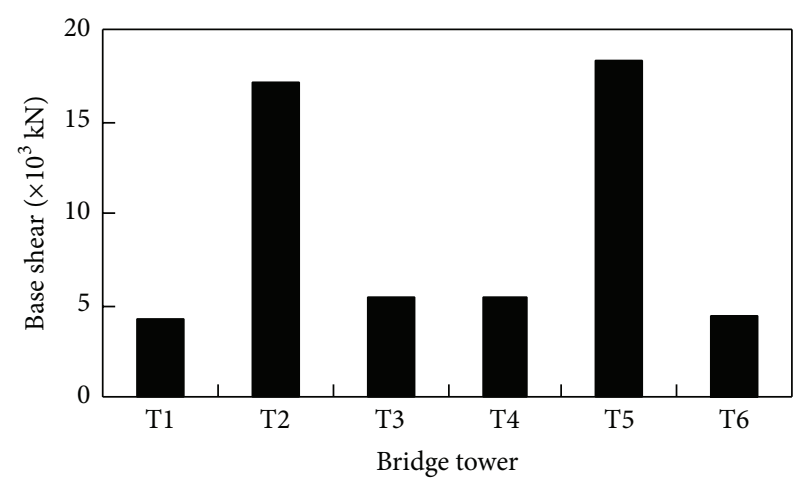

(a)

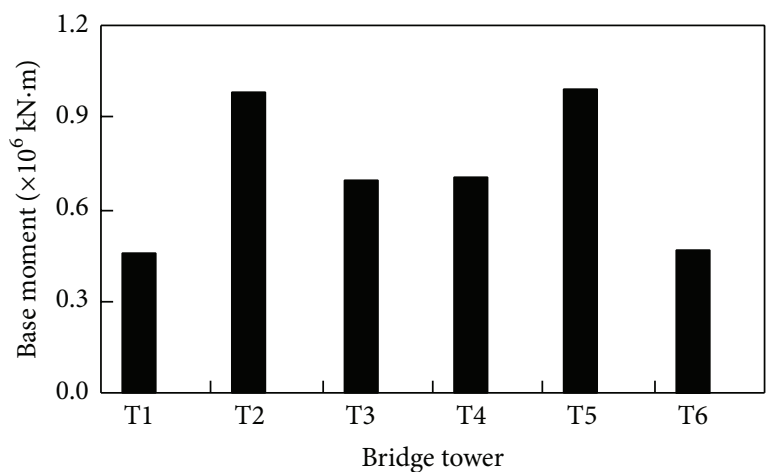

(b)

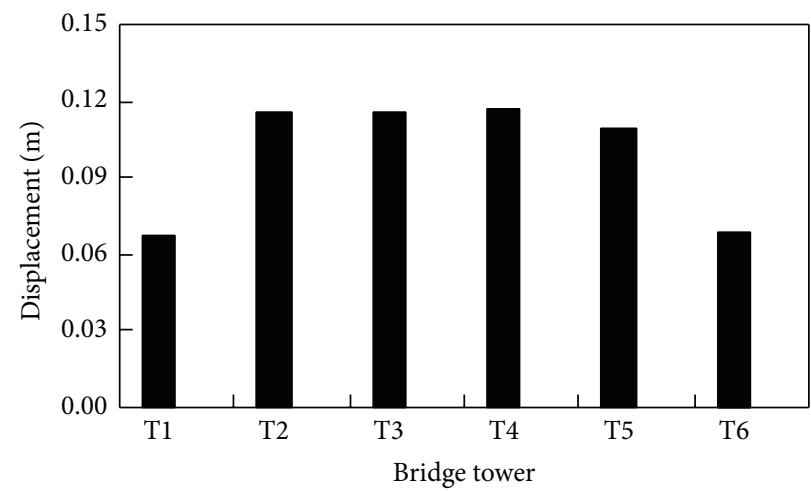

(c)

FIGURE 9: RMS longitudinal buffeting responses of bridge towers. (a) RMS base shear, (b) RMS base moment, and (c) RMS top displacements of bridge towers.

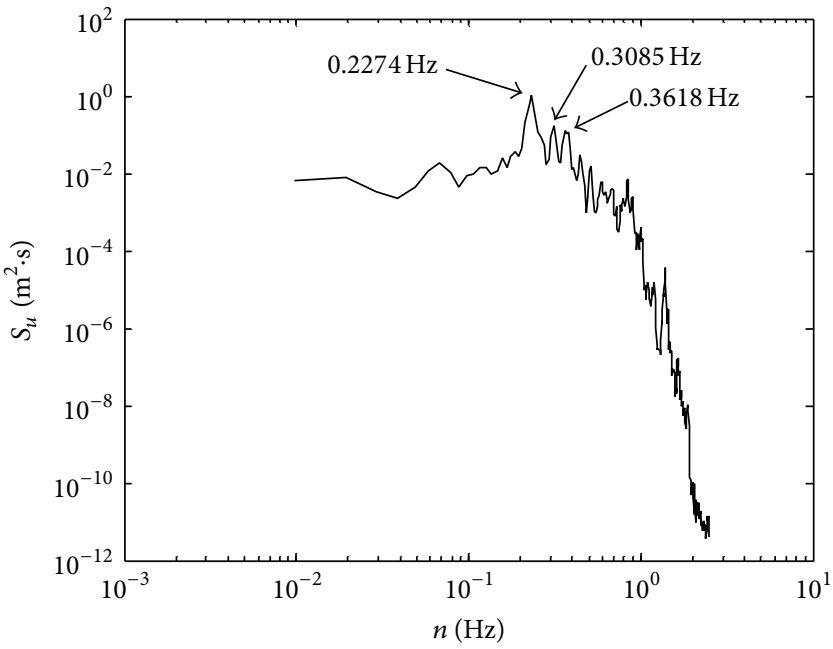

(a)

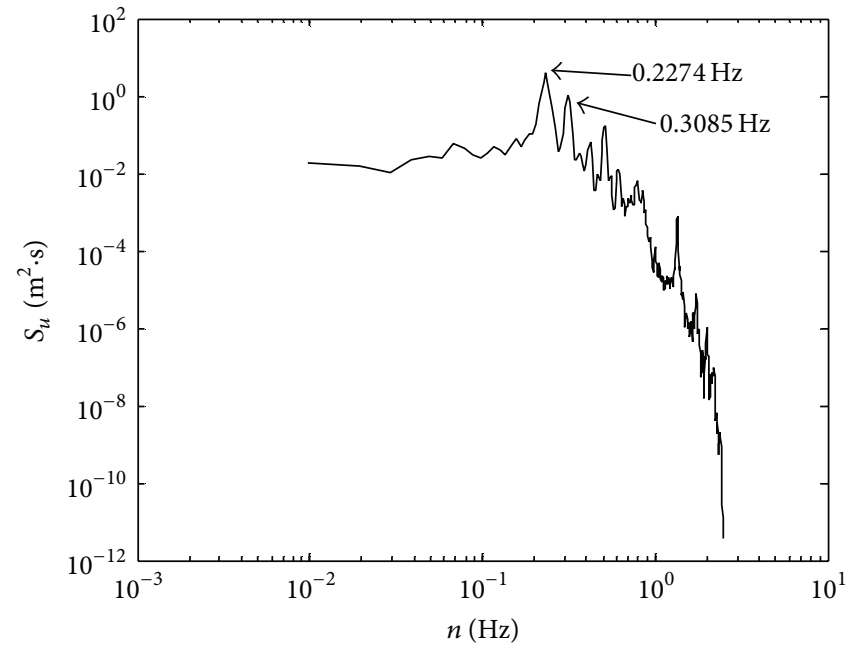

(b)

FIGURE 10: Power spectra of longitudinal buffeting responses. (a) Longitudinal buffeting displacement on the top of bridge tower number 3 and (b) vertical buffeting displacement in the middle of bridge deck.

(iii) The top displacements of bridge towers are highly correlated with vertical displacements of bridge deck. Figure 10 further shows the power spectrum of longitudinal buffeting displacement on the top of bridge tower number 3 and power spectrum of vertical buffeting displacement in the middle of the bridge deck. It can be seen that the first and second peaks in both two power spectra correspond to the 1st and 9th vibration mode, which are all coupling modes of vertical bending of the bridge deck and longitudinal bending of bridge tower. 


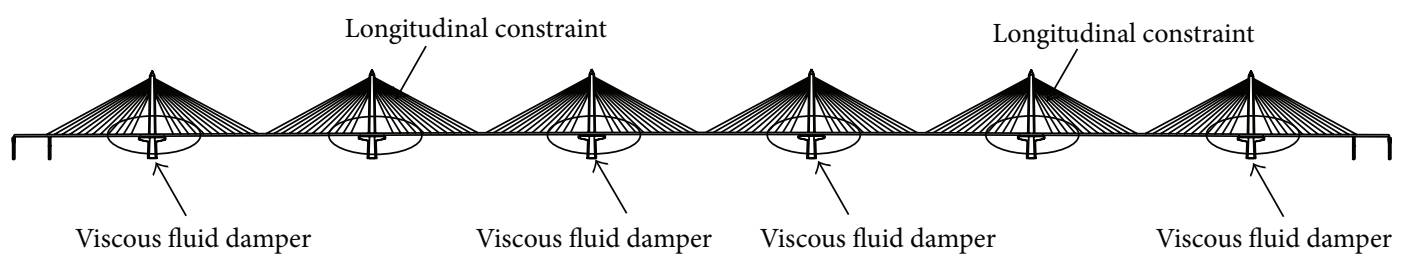

FIGURE 11: Installation of viscous fluid dampers in the bridge.

\section{A Passive Control System for Mitigation of Longitudinal Buffeting Responses}

5.1. Parametric Study on Viscous Fluid Dampers. Passive dampers have attracted the particular attention of structural control engineers due to their reliability and ease of implementation. Previous investigations have demonstrated the effectiveness of passive dampers in reducing the seismic responses of long-span cable-stayed bridges [17-19]. And Domaneschi and Martinelli [20,21] provide a passive control method for mitigation of transverse buffeting responses of a long-span suspension bridge. Therefore, it would be interesting to investigate the application of passive dampers such as viscous fluid dampers in reducing the longitudinal buffeting responses of the multitower cable-stayed bridge. In this section, a parametric study is performed to investigate the effects of viscous fluid dampers on the mitigation of longitudinal buffeting responses of the multispan cablestayed bridge. In a viscous fluid damper, the damping force $f$ is described as [22]

$$
f=c|v|^{\alpha} \operatorname{sgn}(v),
$$

where $c$ is the damping coefficient of the damper; $\alpha$ is the velocity exponent of the damper; $v$ is the relative velocity across the damper. From (8), the damping coefficient and the velocity exponent are the two parameters that govern the selection of a viscous fluid damper. In the present study, the velocity exponent $\alpha$ is varied from 0.1 to 1.0 with the interval of 0.1 . And the damping coefficient $c$ is varied from 2000 to $12000 \mathrm{kN} \cdot(\mathrm{s} / \mathrm{m})^{\alpha}$ with the interval of $1000 \mathrm{kN} \cdot(\mathrm{s} / \mathrm{m})^{\alpha}$. Considering the configuration of the multispan cable-stayed bridge with the partially longitudinal constraint system, the viscous fluid dampers are placed at the bridge towers longitudinally unrestricted with the bridge deck, that is, towers number 1 , number 3 , number 4, and number 6 in Jiashao Bridge as shown in Figure 11. The buffeting responses of the bridge using the viscous fluid dampers are calculated. For instance, Figure 12 shows the comparisons of time-histories of vertical buffeting displacement in the middle of the girder span between bridge towers number 3 and number 4 with and without viscous fluid dampers with regard to the parameters of the dampers $\alpha=0.3$ and $c=5000 \mathrm{kN} \cdot(\mathrm{s} / \mathrm{m})^{0.3}$.

A parametric study is performed to investigate the effects of variations in damping coefficient $c$ and velocity exponent $\alpha$ of viscous fluid dampers on the buffeting responses of the bridge. To evaluate the effectiveness of passive viscous dampers, evaluation criteria $J_{1}-J_{4}$ are selected, where $J_{1}=$ RMS base shear of towers, $J_{2}=$ RMS base moment of

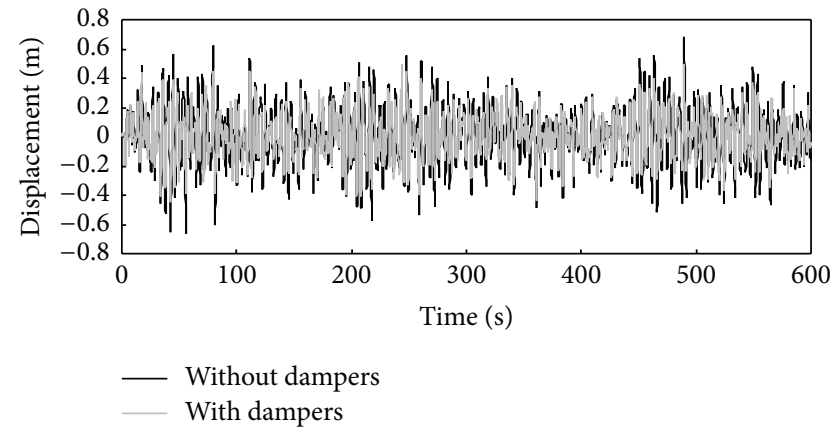

FIGURE 12: Comparisons of time-history of vertical buffeting displacement with and without dampers.

towers, $J_{3}=$ RMS top displacement of towers, and $J_{4}=$ RMS vertical displacement of bridge deck. To compare the response quantities of the bridge with and without passive viscous dampers, criteria reduction factor $R_{J i}$ is further defined as

$$
R_{J i}=\frac{J_{i 0}-J_{i}}{J_{i 0}} \times 100 \%, \quad i=1,2,3,4,
$$

where $J_{i}$ and $J_{i 0}$ are $i$ th evaluation criteria of the bridge with passive viscous dampers and the uncontrolled bridge, respectively.

Figure 13 shows the plots of the criteria reduction factors $R_{J 1}$ of the bridge with passive viscous dampers. It can be seen from Figures 13(a) and 13(c) that, for all the velocity exponents $\alpha$, the criteria reduction factors $R_{J 1}$ for the RMS base shears of bridge towers number 1 and number 3 decrease with increasing damping coefficient $c$ of the viscous fluid dampers. And for small velocity exponents such as $\alpha=$ 0.1 and 0.2 , the criteria reduction factors $R_{J 1}$ of the towers number 1 and number 3 decrease significantly, which indicates that the installation of viscous fluid dampers results in the significant increases in the base shears of bridge towers longitudinally unrestricted with the bridge deck. It can be seen from Figure 13(b) that, (1) for large velocity exponents such as $\alpha=0.6 \sim 1.0$, the criteria reduction factor $R_{J 1}$ increases with an increasing in damping coefficient $c$; (2) for medium velocity exponents such as $\alpha=0.2 \sim 0.5$, the criteria reduction factor $R_{J 1}$ increases with an increase in damping coefficient $c$ up to a certain level, giving maximum values for the criteria reduction factor $R_{J 1}$; (3) for small velocity exponents such as $\alpha=0.1$, the criteria reduction factor $R_{J 1}$ decreases with an increase in damping coefficient $c$. On the whole, the maximum criteria reduction factor $R_{J 1}$ 


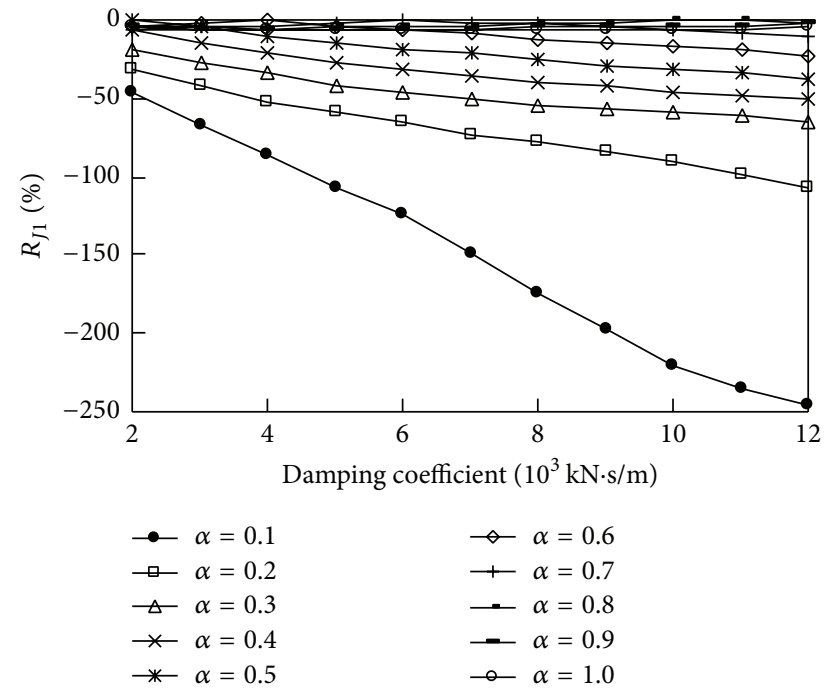

(a)

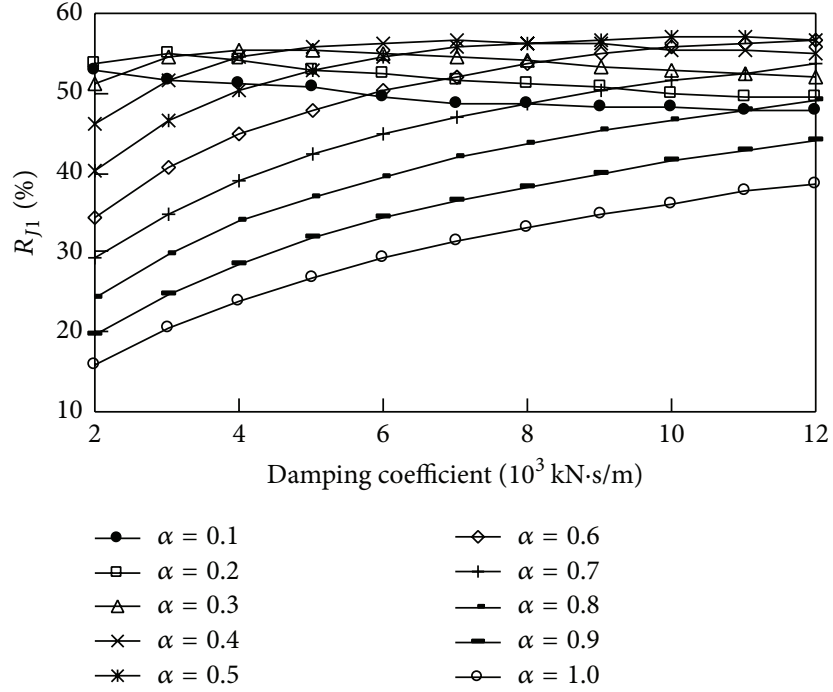

(b)

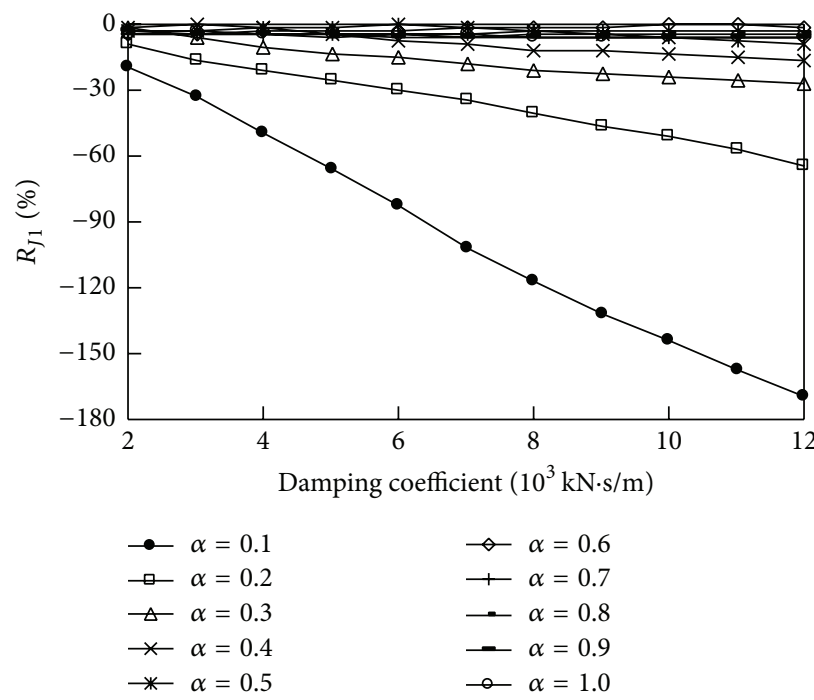

(c)

FIGURE 13: Criteria reduction factor $R_{J 1}$ for the RMS base shears of towers. (a) $R_{J 1}$ of tower number 1, (b) $R_{J 1}$ of tower number 2, and (c) $R_{J 1}$ of tower number 3.

is approximately the same for different damping exponent $\alpha$. Moreover, the smaller the damping exponent $\alpha$, the smaller the damping coefficient $c$ corresponding to the maximum criteria reduction factor $R_{I 1}$. The maximum criteria reduction factor $R_{I 1}$ for the RMS base shear of tower number 2 is $57.01 \%$, which indicates that the installation of viscous fluid dampers results in a reasonable reduction in base shears of bridge towers longitudinally restricted with the bridge deck.

Figure 14 shows the plots of the criteria reduction factors $R_{I 2}$ of the bridge with passive viscous dampers. It can be seen from Figure 14(a) that, for small velocity exponents such as $\alpha=0.1$ and 0.2 , the criteria reduction factor $R_{I 2}$ of the tower number 1 decreases significantly, which will result in the significant increase in the base moment of side tower number 1 . However, for other velocity exponents the criteria reduction factor $R_{J 2}$ of the tower number 1 increases slightly.
It can be seen from Figures 14(b) and 14(c) that the effects of variations in parameters of the viscous fluid dampers on the criteria reduction factors $R_{J 2}$ of the towers number 2 and number 3 are similar to the criteria reduction factor $R_{J 1}$ of tower number 2 . The maximum criteria reduction factors $R_{I 2}$ for the RMS base moment of towers number 2 and number 3 are $57.88 \%$ and $28.63 \%$, respectively.

Figures 15 and 16 show the plots of the criteria reduction factors $R_{J 3}$ and $R_{J 4}$ of the bridge with passive viscous dampers. It can be observed from Figures 15 and 16 that the effects of variations in parameters of the viscous fluid dampers on the criteria reduction factors $R_{J 3}$ and $R_{J 4}$ are similar to the criteria reduction factor $R_{J 1}$ of tower number 2. The maximum criteria reduction factors $R_{J 3}$ for the RMS top displacement of towers number 1 , number 2 , and number 3 are $7.71 \%, 18.20 \%$, and $23.90 \%$, respectively. And 


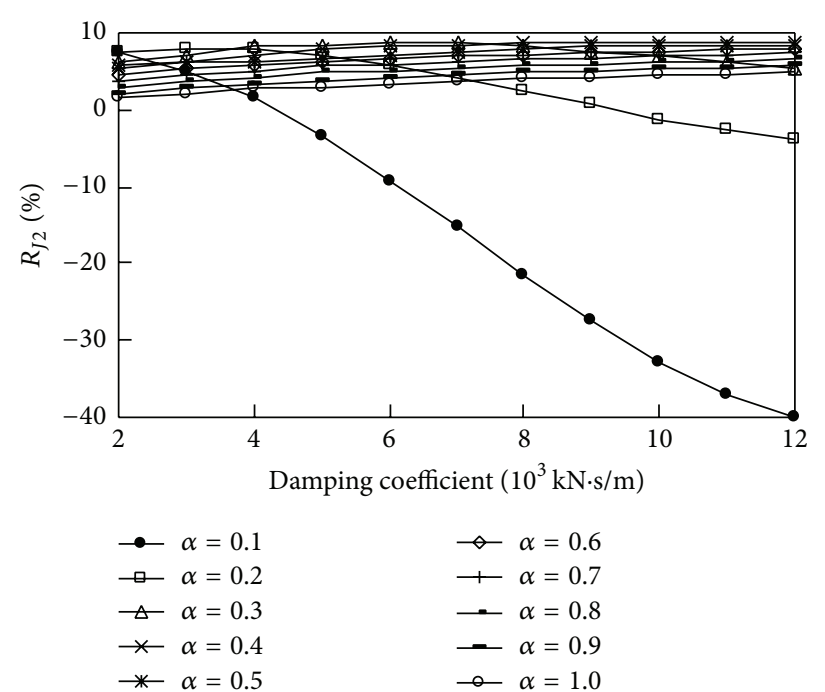

(a)

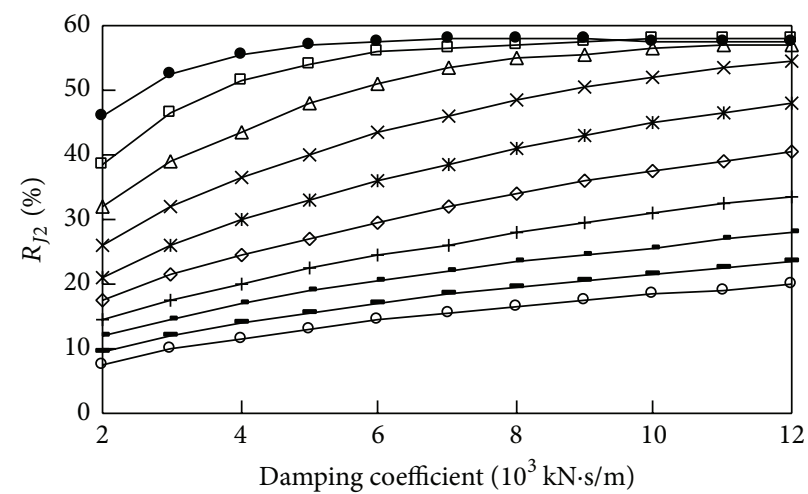

$$
\begin{aligned}
& \rightarrow \alpha=0.1 \\
& \rightarrow \alpha=0.2 \\
& \triangle \quad \alpha=0.3 \\
& \rightarrow \alpha=0.4 \\
& \rightarrow \alpha=0.5
\end{aligned}
$$$$
\begin{aligned}
& -\alpha=0.6 \\
& -\alpha=0.7 \\
& -\alpha=0.8 \\
& -\alpha=0.9 \\
& -\alpha \quad \alpha=1.0
\end{aligned}
$$

(b)

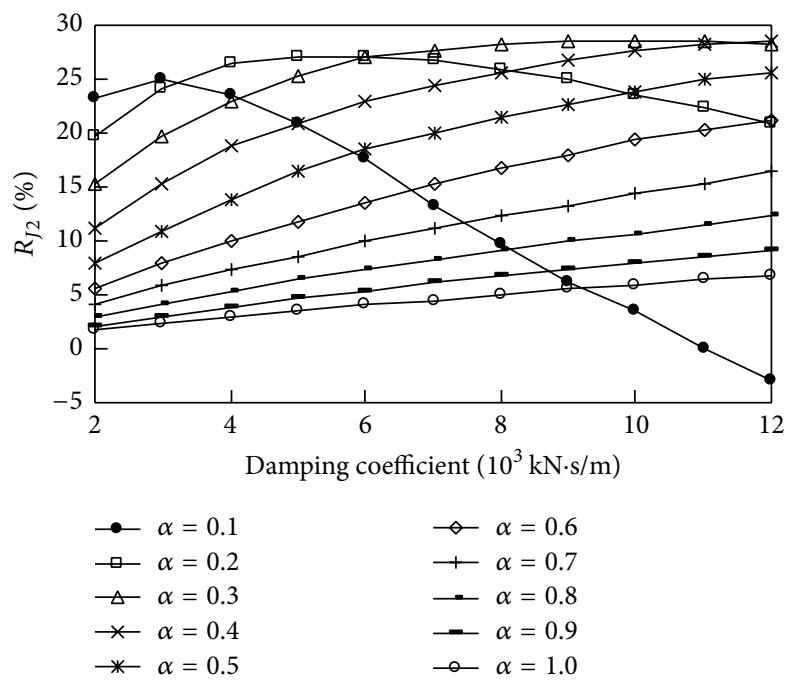

(c)

FIGURE 14: Criteria reduction factor $R_{J 2}$ for the RMS base moments of towers. (a) $R_{J 2}$ of tower number 1, (b) $R_{J 2}$ of tower number 2, and (c) $R_{J 2}$ of tower number 3 .

the maximum criteria reduction factors $R_{J 4}$ for the RMS vertical displacement in the middle of three girder spans between towers number 1 and number 2 , number 2 and number 3, and number 3 and number 4 are 13.43\%, 21.74\%, and $24.13 \%$, respectively.

Table 5 summarizes the extreme values and the average values for the criteria reduction factors $R_{J 1} \sim R_{J 4}$. The analytical investigations for the mitigation of longitudinal buffeting responses of the multispan cable-stayed bridge using viscous fluid dampers indicate the following: (1) The large base shears and moments of bridge towers longitudinally restricted with the bridge deck are significantly reduced. However, inappropriate parameters $c$ and $\alpha$ of the viscous fluid dampers will result in significant increases in the base shears and moments of bridge towers longitudinally unrestricted with the bridge deck. (2) The RMS top displacements of central towers and vertical displacements of the bridge deck can be effectively reduced so that the large longitudinal buffeting responses of the bridge due to insufficient longitudinal stiffness of the central towers can be improved using viscous fluid dampers.

\subsection{Optimization Design of Passive Control System}

5.2.1. Multiobjective Optimization Problem. The optimization design of vibration control with passive dampers is necessary for practical application [23]. As shown in Figures 13 16, individual optimal solutions for each criteria reduction factor are obviously different for the mitigation of longitudinal buffeting responses of the multispan cable-stayed bridge using viscous fluid dampers. For example, as shown in Figure 13 it is impossible to meet minimum base shears of bridge towers longitudinally restricted with the bridge deck such as tower number 2 and minimum base shears 


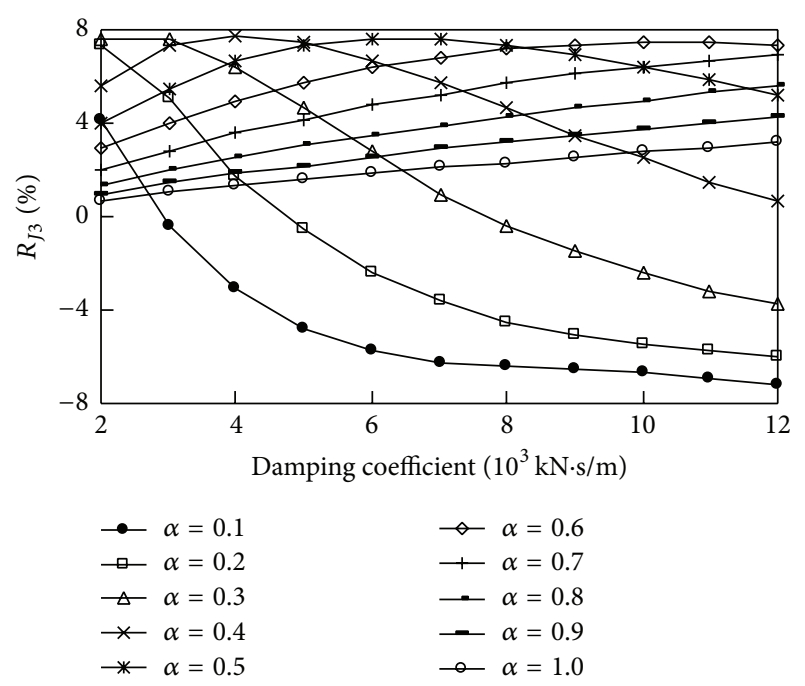

(a)

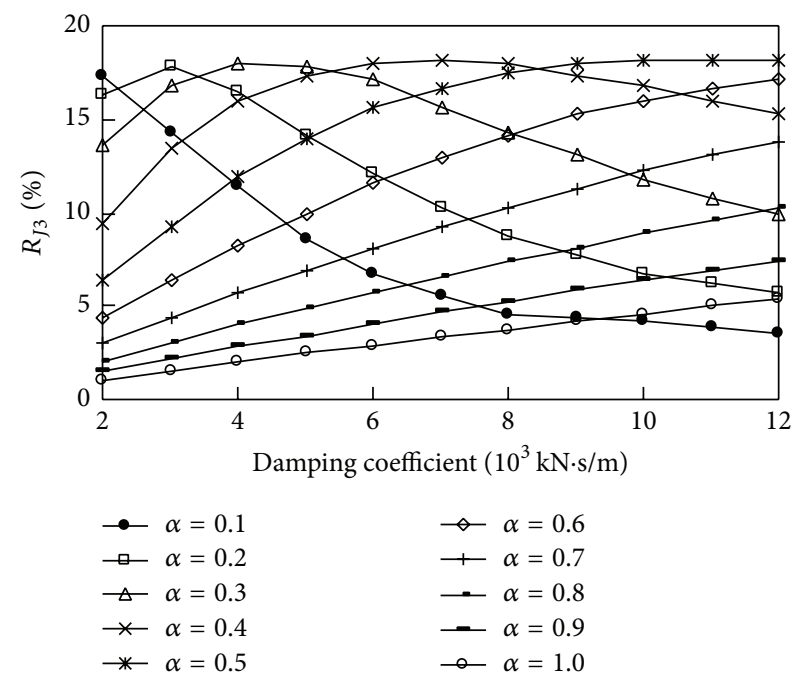

(b)

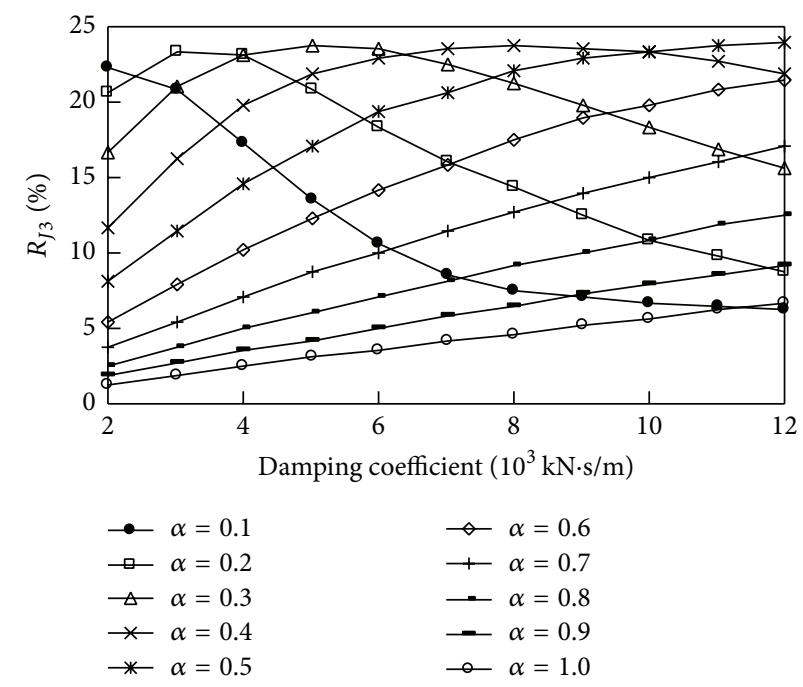

(c)

FIGURE 15: Criteria reduction factor $R_{J 3}$ for the RMS top displacements of towers. (a) $R_{J 3}$ of tower number 1, (b) $R_{J 3}$ of tower number 2, and (c) $R_{J 3}$ of tower number 3 .

of bridge towers longitudinally unrestricted with the bridge deck such as towers number 1 and number 3. Thus, none of the optimal solutions allows simultaneous optimizations for the base shears of all of bridge towers simultaneously, which indicates that multiobjective optimization is necessary to obtain acceptable solutions. Multiobjective optimization provides a family of equally valid solutions (Pareto-optimal solutions) rather than a single optimal solution. As shown in Figure 17, a trade-off exists between the objectives such that an improvement in one objective cannot be achieved without detriment to another [16]. The nondominating sort genetic algorithm II (NSGA-II), which is well-adopted in multiobjective optimization, is used in the present study. Deb et al. [24] have proposed an elitist, fast, and parameterfree multiobjective optimization genetic algorithm (NSGAII). Specific details of the NSGA-II can be referenced in Deb et al. [24].
5.2.2. NSGA-II-Optimized Parameters for Viscous Fluid Damper. In this section, the optimization design method based on the NSGA-II is proposed to determine the optimized parameters $c$ and $\alpha$ of the viscous fluid dampers for the mitigation of longitudinal buffeting responses of the multispan cable-stayed bridge. As discussed in Section 5.2.1, the optimization design objective is to yield maximum reductions in the top displacements of central towers and base forces of bridge towers longitudinally restricted with the bridge deck, with hampering the significant gain achieved in the base forces of bridge towers longitudinally unrestricted with the bridge deck. Meanwhile, the favorable controlling effect on the vertical displacements of bridge deck is also worthy of attention. Therefore, a summary of the objective functions used in this study is given in Table 6. When the optimization is started, NSGA-II generates an initial population of chromosomes, each of which represents a set of 


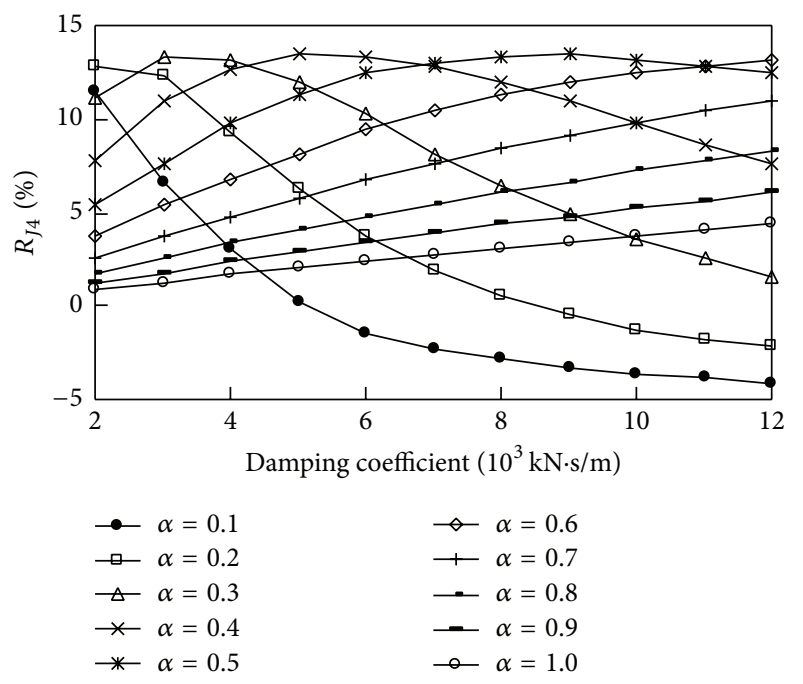

(a)

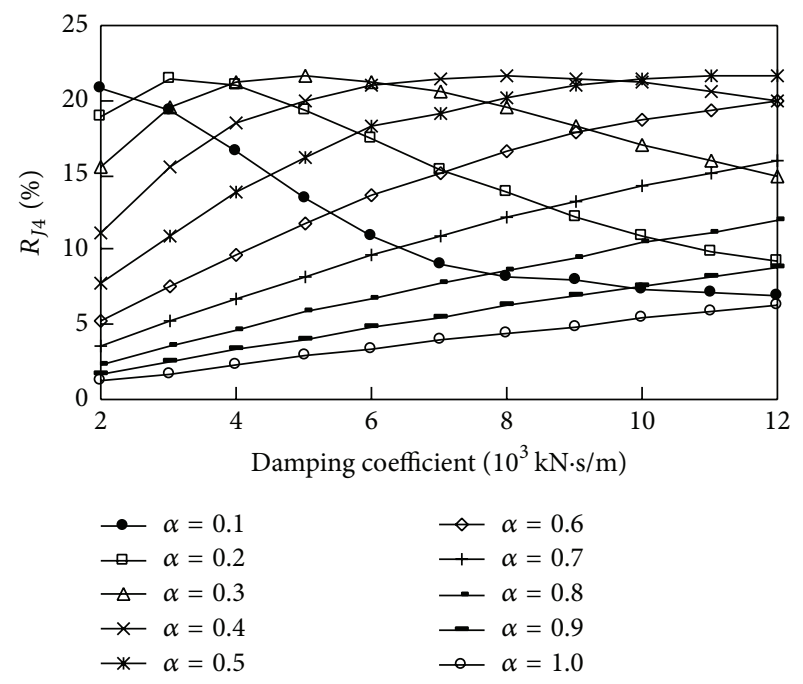

(b)

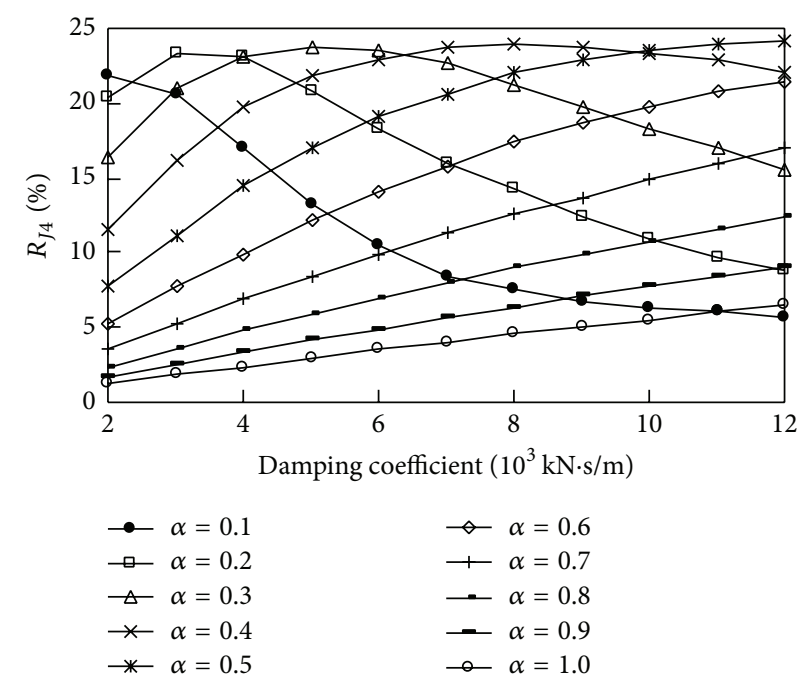

(c)

FIGURE 16: Criteria reduction factor $R_{J 4}$ for the RMS vertical displacements of bridge deck. (a) $R_{J 4}$ in the middle of girder span between towers number 1 and number 2, (b) $R_{I 4}$ in the middle of girder span between towers number 2 and number 3 , and (c) $R_{I 4}$ in the middle of girder span between towers number 3 and number 4 .

parameters $c$ and $\alpha$ of the viscous fluid dampers. In this study, the initial population size is taken to contain 25 individuals. Next, NSGA-II creates a new generation of chromosomes based on multiobjective ranking using several simple GA operators such as selection, crossover, and mutation. As the number of generations increases, the control performance of the elite (i.e., nondominated) individuals is improved because of elitism [16]. In this study, an upper limit on the number of generations is specified to be 50 . The final number of nondominated individuals obtained after optimization is 19 . Pareto-optimal fronts between different objectives are shown in Figure 18.

As shown in Figures 18(a) 18(d), the objective $f_{1}$ is equivalent to the objectives $f_{2}, f_{3}, f_{4}$, and $f_{5}$, respectively. Thus, after multiobjective optimization the maximum reduction in the top displacement of central tower number 2 can also results in the maximum reductions in the vertical displacements of bridge deck, base forces of tower number 2 , and base moment of tower number 1 . Such optimization results are largely due to the coupling effects of vertical bending of the bridge deck and longitudinal bending of bridge tower. However, as shown in Figures 18(b), 18(d), and 18(e), the base shear of tower number 1 is in competition with the top displacement of tower number 2 and base forces of tower number 2. Here, one set effectively controls the base forces of bridge towers longitudinally restricted with the bridge deck and the top displacements of central towers but sacrifices control of base shears of bridge towers longitudinally unrestricted with the bridge deck. Thus, there is no individual that can appropriately reduce base shears of all of bridge towers. And the objectives $f_{1}, f_{2}, f_{3}, f_{4}$, and $f_{5}$ can be improved at the cost of the degraded objective $f_{6}$. 
TABLE 5: Statistical results for the criteria reduction factors $R_{I 1} \sim R_{I 4}$.

\begin{tabular}{|c|c|c|c|}
\hline $\begin{array}{l}\text { Criteria reduction } \\
\text { factor }\end{array}$ & $\begin{array}{l}\text { Maximum } \\
(\%)\end{array}$ & $\underset{(\%)}{\operatorname{Minimum}}$ & $\begin{array}{c}\text { Average } \\
(\%)\end{array}$ \\
\hline $\begin{array}{l}R_{J 1} \text { of tower } \\
\text { number } 1\end{array}$ & -0.29 & -245.89 & -31.25 \\
\hline $\begin{array}{l}R_{J 1} \text { of tower } \\
\text { number } 2\end{array}$ & 57.01 & 15.86 & 42.62 \\
\hline $\begin{array}{l}R_{J 1} \text { of tower } \\
\text { number } 3\end{array}$ & -0.03 & -169.32 & -16.07 \\
\hline $\begin{array}{l}R_{J 2} \text { of tower } \\
\text { number } 1\end{array}$ & 8.93 & -40.18 & 3.90 \\
\hline $\begin{array}{l}R_{J 2} \text { of tower } \\
\text { number } 2\end{array}$ & 57.88 & 7.63 & 32.48 \\
\hline $\begin{array}{l}R_{J 2} \text { of tower } \\
\text { number } 3\end{array}$ & 28.63 & -2.90 & 14.07 \\
\hline $\begin{array}{l}R_{J 3} \text { of tower } \\
\text { number } 1\end{array}$ & 7.71 & -7.14 & 2.56 \\
\hline $\begin{array}{l}R_{J 3} \text { of tower } \\
\text { number } 2\end{array}$ & 18.20 & 1.04 & 7.01 \\
\hline $\begin{array}{l}R_{J 3} \text { of tower } \\
\text { number } 3\end{array}$ & 23.90 & 1.28 & 8.72 \\
\hline $\begin{array}{l}R_{J 4} \text { in the middle } \\
\text { of girder span } \\
\text { between towers } \\
\text { number } 1 \text { and } \\
\text { number } 2\end{array}$ & 13.43 & -4.16 & 6.32 \\
\hline $\begin{array}{l}R_{J 4} \text { in the middle } \\
\text { of girder span } \\
\text { between towers } \\
\text { number } 2 \text { and } \\
\text { number } 3\end{array}$ & 21.74 & 1.21 & 11.89 \\
\hline $\begin{array}{l}R_{J 4} \text { in the middle } \\
\text { of girder span } \\
\text { between towers } \\
\text { number } 3 \text { and } \\
\text { number } 4\end{array}$ & 24.13 & 1.21 & 12.49 \\
\hline
\end{tabular}

In summary, for mitigation of longitudinal buffeting response of the multispan cable-stayed bridge, a design engineer can choose a set of proper parameters $c$ and $\alpha$ of the viscous fluid dampers from Figure 18 that can satisfy the different performance requirements. If an engineer wants to minimize top displacements of central towers and base forces of bridge towers longitudinally restricted with the bridge deck regardless of base shear of tower number 1, the most appropriate parameters $c$ and $\alpha$ of the viscous fluid dampers can be selected as the set A presented in Figure 18. If an engineer wants to control the base shear of tower number 1 with no increase or medium increase, the sets $\mathrm{C}$ or $\mathrm{B}$ presented in Figure 18 can be selected. Table 7 shows the control effects using three sets of A, B, and C.

\section{Conclusions}

The Jiaoshao Bridge in China is a six-tower cable-stayed bridge, which is the longest multispan cable-stayed bridge in the world. In this paper, the longitudinal buffeting responses of the bridge were obtained using a time-domain procedure

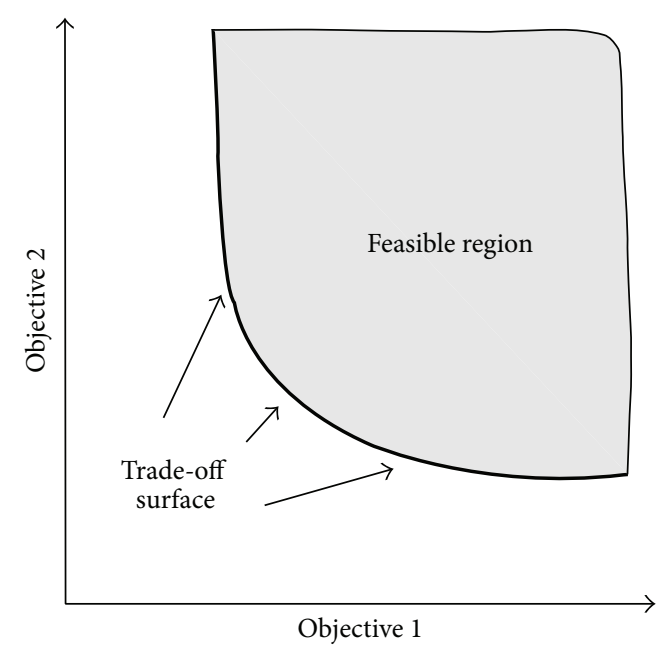

FIGURE 17: Trade-off between two competing objectives [16].

TABLE 6: Six objective functions.

\begin{tabular}{lc}
\hline Number & Description \\
\hline$f_{1}$ & $R_{J 3}$ for the RMS top displacement of tower number 2 \\
$f_{2}$ & $R_{J 4}$ for the RMS vertical displacement in the middle of \\
$f_{3}$ & girder span between towers number 2 and number 3 \\
$f_{4}$ & $R_{J 2}$ for the RMS base moment of tower number 2 \\
$f_{5}$ & $R_{J 2}$ for the RMS base moment of tower number 1 \\
$f_{6}$ & $R_{J 1}$ for the RMS base shear of tower number 2 \\
\hline
\end{tabular}

for analyzing buffeting responses implemented in ANSYS and the performance of viscous fluid dampers for the mitigation of longitudinal buffeting responses is further investigated. From the analytical results of the present study the following conclusions are drawn:

(1) Due to the insufficient longitudinal stiffness of the central towers, the longitudinal top displacements of central towers are significantly larger than those of side towers in the multispan cable-stayed bridge. The installations of viscous fluid dampers are beneficial for the reductions in the longitudinal top displacements of central towers. Due to the coupling modes of vertical bending of the bridge deck and longitudinal bending of bridge tower, the vertical displacements of the bridge deck can also be effectively reduced using viscous fluid dampers.

(2) In the multispan cable-stayed bridge, part of bridge towers longitudinally restricted with the bridge deck results in the concentration effect of longitudinal base shears and moments. The base shears and moments of bridge towers longitudinally restricted with the bridge deck are significantly larger than those of bridge towers longitudinally unrestricted with the bridge deck. The large base shears and moments of bridge towers longitudinally restricted with the bridge deck are significantly reduced using viscous 


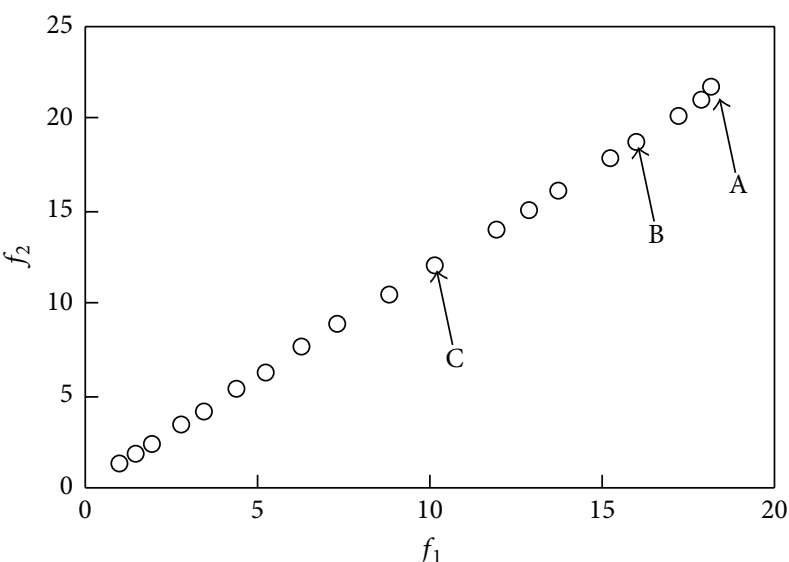

(a)

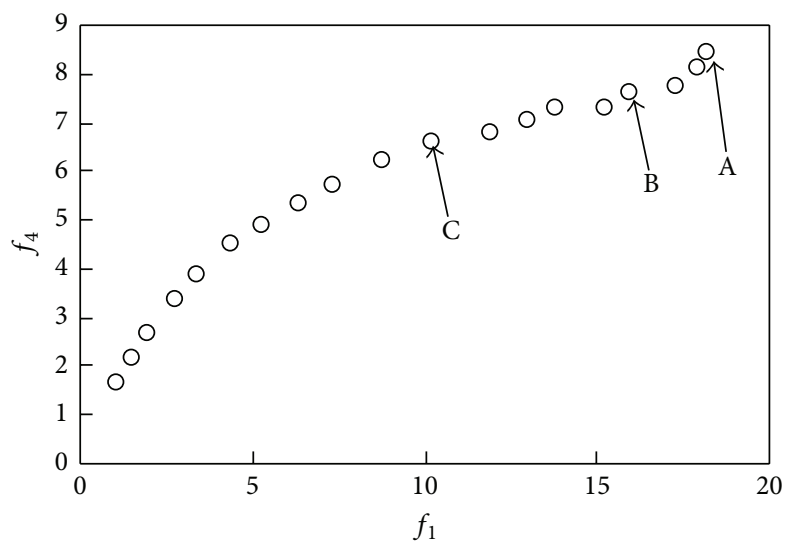

(c)

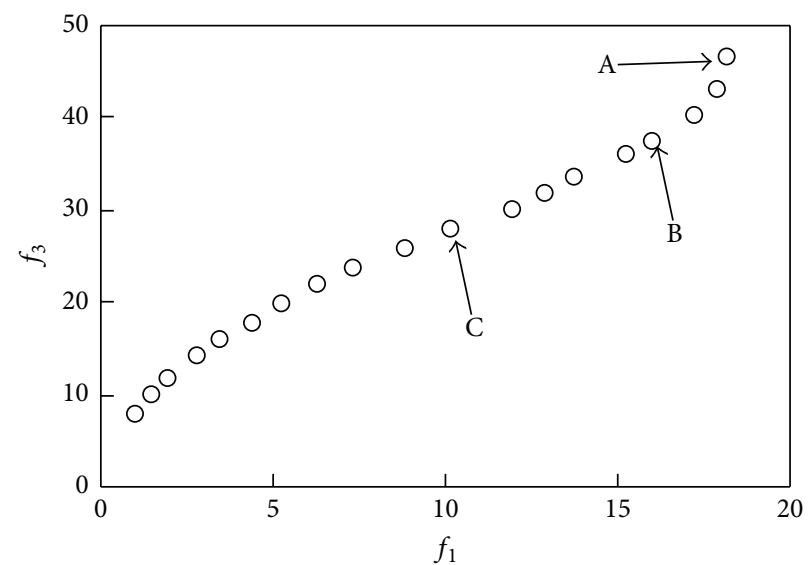

(b)

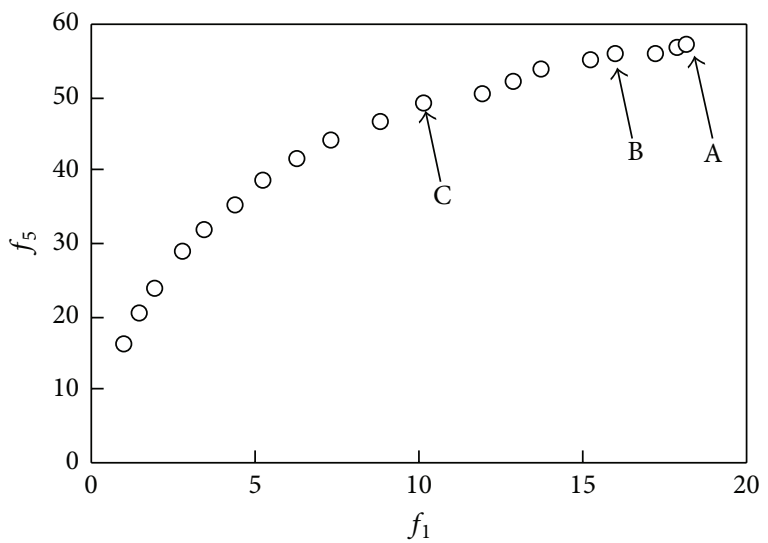

(d)

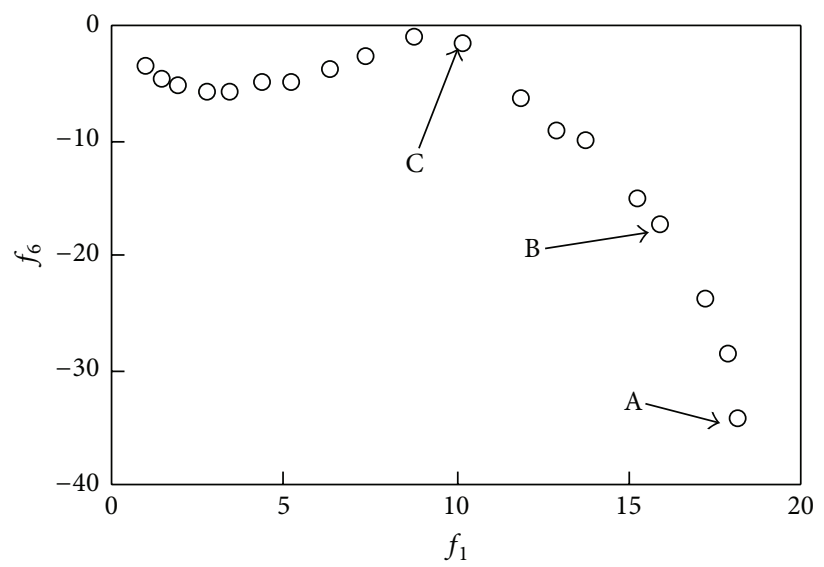

(e)

Figure 18: Pareto-optimal fronts. (a) $f_{1}-f_{2}$, (b) $f_{1}-f_{3}$, (c) $f_{1}-f_{4}$, (d) $f_{1}-f_{5}$, and (e) $f_{1}-f_{6}$.

fluid dampers. However, inappropriate parameters of the viscous fluid dampers will result in significant increases in the base shears and moments of bridge towers longitudinally unrestricted with the bridge deck.

(3) The optimization design objective is to yield maximum reductions in the top displacements of central towers and base forces of bridge towers longitudinally restricted with the bridge deck, with hampering the significant gain achieved in the base forces of bridge towers longitudinally unrestricted with the bridge deck. To this end, a multiobjective optimization design method that uses a nondominating sort genetic algorithm II (NSGA-II) is used to optimize parameters of the viscous fluid dampers. Optimization results reveal that a design engineer can choose a set of proper parameters of the viscous fluid dampers 
TABLE 7: Control effects using three sets of A, B, and C.

\begin{tabular}{|c|c|c|c|}
\hline Criteria reduction factor & $\begin{array}{c}\text { Set } \mathrm{A}(\alpha=0.51, c= \\
\left.11.55 \times 10^{3} \mathrm{kN} \cdot(\mathrm{s} / \mathrm{m})^{0.52}\right) \\
\end{array}$ & $\begin{array}{c}\text { Set B }(\alpha=0.58, c= \\
\left.9.63 \times 10^{3} \mathrm{kN} \cdot(\mathrm{s} / \mathrm{m})^{0.58}\right)\end{array}$ & $\begin{array}{c}\text { Set } \mathrm{C}(\alpha=0.77, c= \\
\left.11.88 \times 10^{3} \mathrm{kN} \cdot(\mathrm{s} / \mathrm{m})^{0.77}\right) \\
\end{array}$ \\
\hline$R_{J 1}$ of tower number 1 & -34.25 & -17.49 & -1.76 \\
\hline$R_{J 1}$ of tower number 2 & 56.95 & 55.59 & 49.04 \\
\hline$R_{J 1}$ of tower number 3 & -7.47 & -0.41 & -4.32 \\
\hline$R_{J 2}$ of tower number 1 & 8.44 & 7.59 & 6.61 \\
\hline$R_{J 2}$ of tower number 2 & 46.41 & 37.33 & 27.92 \\
\hline$R_{J 2}$ of tower number 3 & 24.92 & 19.27 & 12.22 \\
\hline$R_{J 3}$ of tower number 1 & 5.80 & 7.43 & 5.55 \\
\hline$R_{J 3}$ of tower number 2 & 18.14 & 16.01 & 10.20 \\
\hline$R_{J 3}$ of tower number 3 & 23.76 & 19.86 & 12.59 \\
\hline $\begin{array}{l}R_{J 4} \text { in the middle of girder span between towers number } 1 \\
\text { and number } 2\end{array}$ & 12.82 & 12.53 & 8.24 \\
\hline $\begin{array}{l}R_{J 4} \text { in the middle of girder span between towers number } 2 \\
\text { and number } 3\end{array}$ & 21.67 & 18.61 & 11.97 \\
\hline $\begin{array}{l}R_{J 4} \text { in the middle of girder span between towers number } 3 \\
\text { and number } 4\end{array}$ & 23.89 & 19.75 & 12.42 \\
\hline
\end{tabular}

from Pareto-optimal fronts that can satisfy the different performance requirements.

\section{Competing Interests}

The authors declare that there is no conflict of interests regarding the publication of this paper.

\section{Acknowledgments}

The authors gratefully acknowledge the support of the National Basic Research Program of China (973 Program) (no. 2015CB060000), the National Science and Technology Support Program of China (no. 2014BAG07B01), the National Natural Science Foundation of China (nos. 51438002 and 51578138), and the Fundamental Research Funds for the Central Universities (2242016K41066).

\section{References}

[1] M. Virlogeux, "Recent evolution of cable-stayed bridges," Engineering Structures, vol. 21, no. 8, pp. 737-755, 1999.

[2] Y. Q. Ni, J. Y. Wang, and L. C. Lo, "Influence of stabilizing cables on seismic response of a multispan cable-stayed bridge," Computer-Aided Civil and Infrastructure Engineering, vol. 20, no. 2, pp. 142-153, 2005.

[3] C. Barre, O. Flamand, and G. Grillaud, "The Millau viaductspecial wind studies for an exceptional structure," in Proceedings of the 10th International Conference on Wind Engineering, pp. 833-836, Copenhagen, Denmark, June 1999.

[4] P. Papanikolas, "The Rion-Antirion multispan cable-stayed bridge," in Proceedings of the 2nd MIT Conference on Computational Fluid and Solid Mechanics, pp. 548-552, Cambridge, Mass, USA, 2003.

[5] ANSYS, Documentation for ANSYS, Revision 12.0, ANSYS, Canonsburg, Pa, USA, 2009.
[6] H. J. Ernst, "The E-molule of rope with consideration of the dip," The Civil Engineering, vol. 40, no. 1, pp. 52-55, 1965.

[7] Y.-L. Xu, L. Hu, and A. Kareem, "Conditional simulation of nonstationary fluctuating wind speeds for long-span bridges," Journal of Engineering Mechanics, vol. 140, no. 1, pp. 61-73, 2014.

[8] G. Deodatis, "Simulation of ergodic multivariate stochastic processes," Journal of Engineering Mechanics, vol. 122, no. 8, pp. 778-787, 1996.

[9] Y. Cao, H. Xiang, and Y. Zhou, "Simulation of stochastic wind velocity field on long-span bridges," Journal of Engineering Mechanics, vol. 126, no. 1, pp. 1-6, 2000.

[10] A. Chen, X. He, and H. Xiang, "Identification of 18 flutter derivatives of bridge decks," Journal of Wind Engineering and Industrial Aerodynamics, vol. 90, no. 12-15, pp. 2007-2022, 2002.

[11] Z. Q. Chen, Y. Han, X. G. Hua, and Y. Z. Luo, "Investigation on influence factors of buffeting response of bridges and its aeroelastic model verification for Xiaoguan Bridge," Engineering Structures, vol. 31, no. 2, pp. 417-431, 2009.

[12] H. Wang, A. Q. Li, and R. M. Hu, "Comparison of ambient vibration response of the Runyang Suspension Bridge under skew winds with time-domain numerical predictions," Journal of Bridge Engineering, vol. 16, no. 4, pp. 513-526, 2011.

[13] H. L. Liao, Report on Wind Tunnel Tests of Sectional Model of Jiashao Bridge, Research Centre for Wind Engineering of Southwest Jiaotong University, Chengdu, China, 2009 (Chinese).

[14] X. G. Hua and Z. Q. Chen, "Full-order and multimode flutter analysis using ANSYS," Finite Elements in Analysis and Design, vol. 44, no. 9-10, pp. 537-551, 2008.

[15] H. Wang, R. Hu, J. Xie, T. Tong, and A. Li, "Comparative study on buffeting performance of sutong bridge based on design and measured spectrum," Journal of Bridge Engineering, vol. 18, no. 7, pp. 587-600, 2013.

[16] H.-S. Kim and P. N. Roschke, "Fuzzy control of base-isolation system using multi-objective genetic algorithm," ComputerAided Civil and Infrastructure Engineering, vol. 21, no. 6, pp. 436-449, 2006.

[17] M. Domaneschi, "Feasible control solutions of the ASCE benchmark cable-stayed bridge," Structural Control and Health Monitoring, vol. 17, no. 6, pp. 675-693, 2010. 
[18] M. Domaneschi and L. Martinelli, "Performance comparison of passive control schemes for the numerically improved ASCE cable-stayed bridge model," Earthquake and Structures, vol. 3, no. 2, pp. 181-201, 2012.

[19] Y. Fujino and D. Siringoringo, "Vibration mechanisms and controls of long-span bridges: a review," Structural Engineering International, vol. 23, no. 3, pp. 248-268, 2013.

[20] M. Domaneschi and L. Martinelli, "Optimal passive and semiactive control of a wind excited suspension bridge," Structure and Infrastructure Engineering, vol. 9, no. 3, pp. 242-259, 2013.

[21] M. Domaneschi and L. Martinelli, "Refined optimal passive control of buffeting-induced wind loading of a suspension bridge," Wind and Structures, vol. 18, no. 1, pp. 1-20, 2014.

[22] Z. Q. Lang, P. F. Guo, and I. Takewaki, "Output frequency response function based design of additional nonlinear viscous dampers for vibration control of multi-degree-of-freedom systems," Journal of Sound and Vibration, vol. 332, no. 19, pp. 44614481, 2013.

[23] Y. Murakami, K. Noshi, K. Fujita, M. Tsuji, and I. Takewaki, "Simultaneous optimal damper placement using oil, hysteretic and inertial mass dampers," Earthquake and Structures, vol. 5, no. 3, pp. 261-276, 2013.

[24] K. Deb, A. Pratap, S. Agarwal, and T. Meyarivan, "A fast and elitist multiobjective genetic algorithm: NSGA-II," IEEE Transactions on Evolutionary Computation, vol. 6, no. 2, pp. 182-197, 2002. 


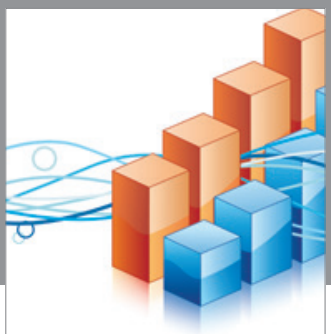

Advances in

Operations Research

vatem alat4

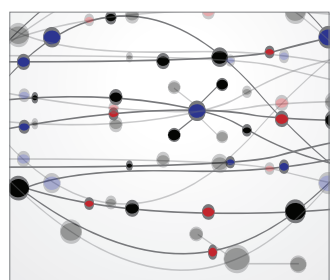

\section{The Scientific} World Journal
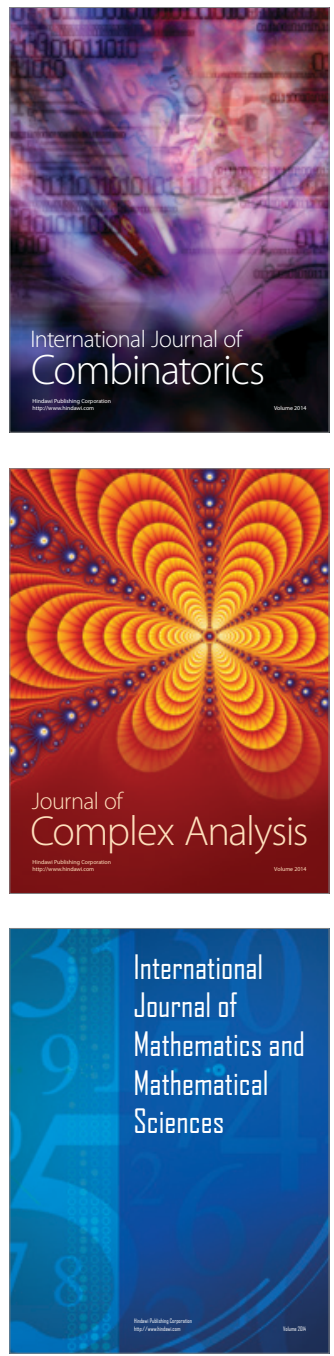
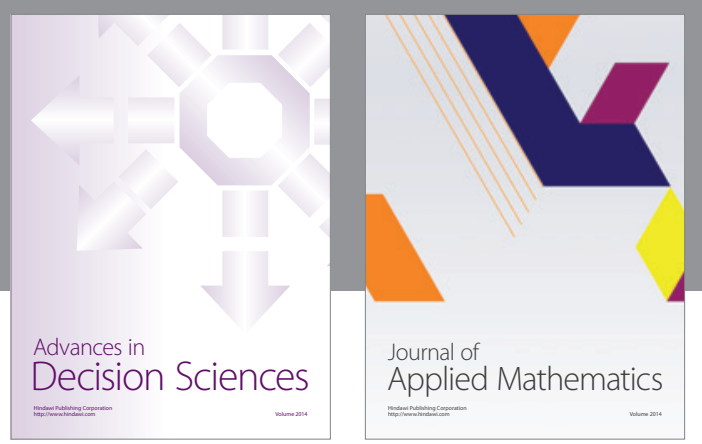

Algebra

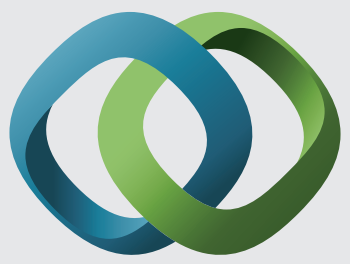

\section{Hindawi}

Submit your manuscripts at

http://www.hindawi.com
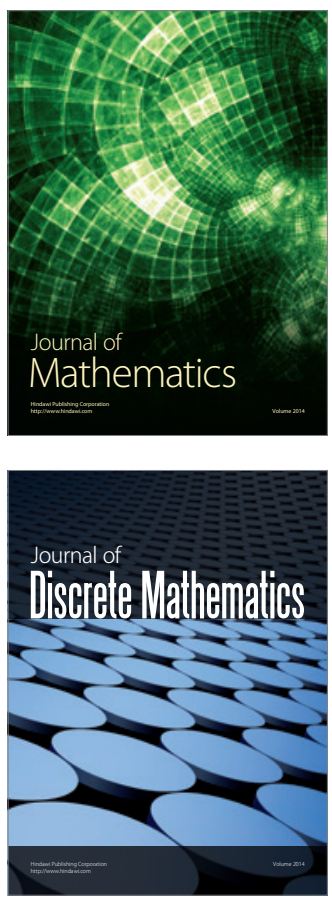

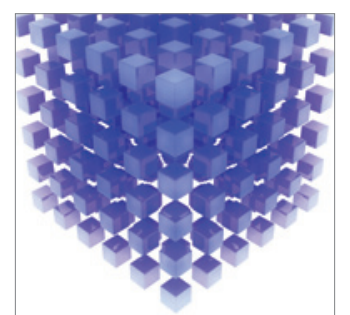

Mathematical Problems in Engineering
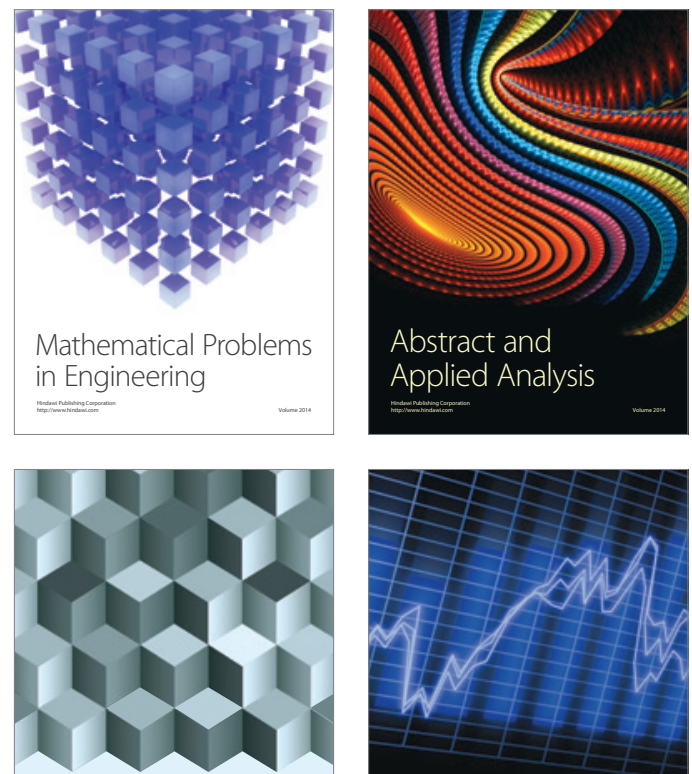

Journal of

Function Spaces

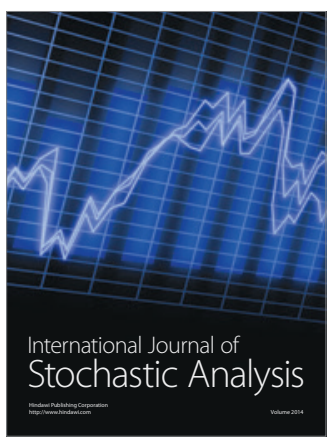

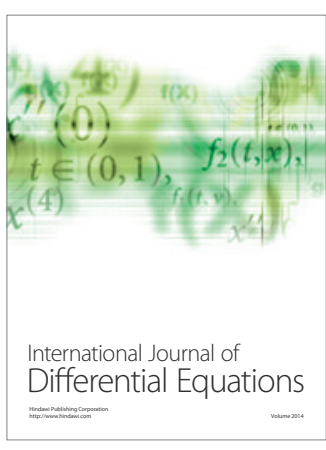
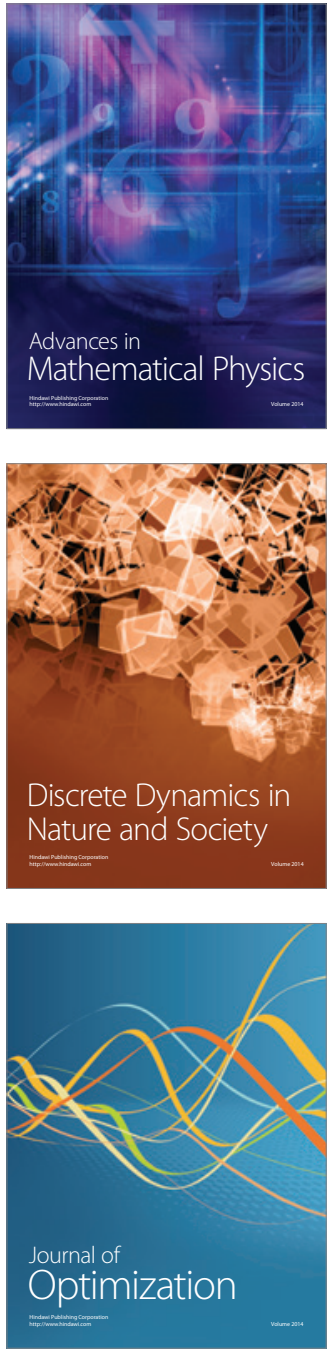